\title{
$N^{0} 10$
}
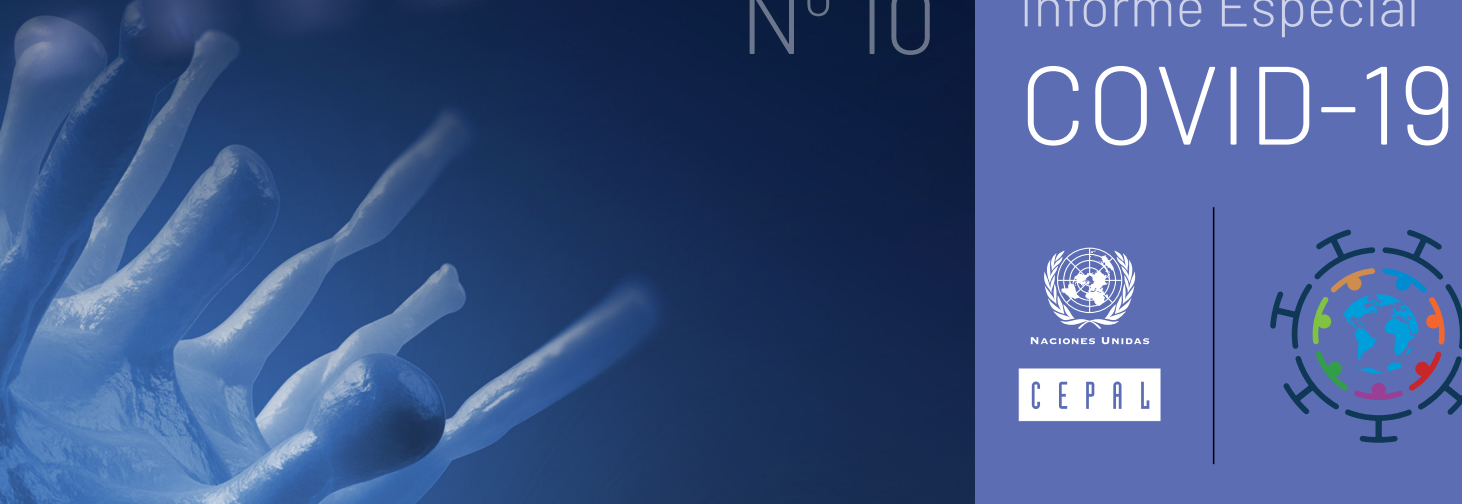

\section{Financiamiento para el desarrollo en la era de la pandemia de COVID-19 y después}

\author{
Prioridades de América Latina y el Caribe \\ en la agenda de políticas mundial en materia \\ de financiamiento para el desarrollo
}

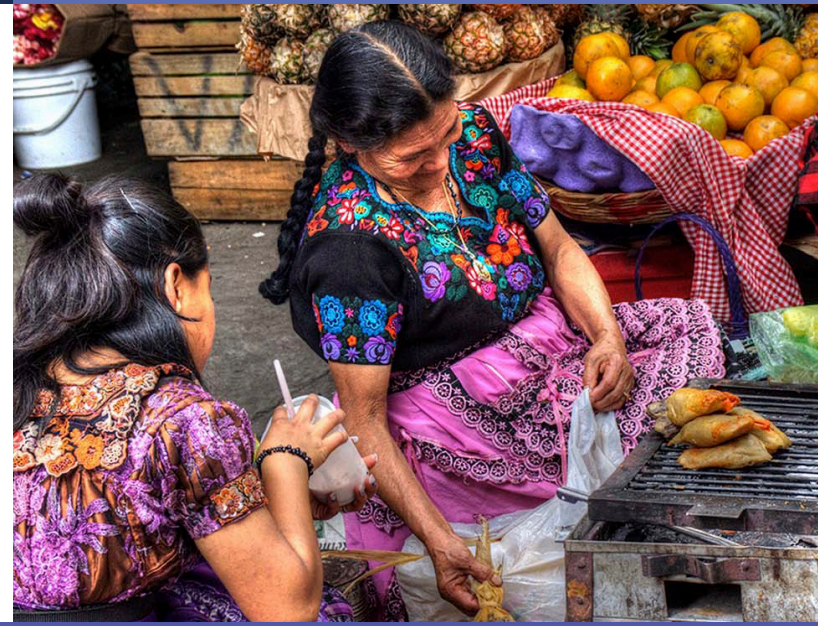

Introducción ${ }^{1}$

- En 2020, América Latina y el Caribe se enfrentó a la peor crisis de la que se tenga constancia y a la mayor contracción económica del mundo en desarrollo (el PIB y la inversión se redujeron un 7,7\% y un $20 \%$, respectivamente) $)^{2}$. Los datos disponibles también muestran que la caída de la inversión respecto de la del PIB fue mayor en América Latina y el Caribe que en otras regiones en desarrollo ${ }^{3}$.

- La pandemia de enfermedad por coronavirus (COVID-19) ha profundizado las brechas estructurales e institucionales de América Latina y el Caribe ${ }^{4}$. La crisis ha afectado gravemente las estructuras productivas y el mercado laboral: más de 2,7 millones de empresas han cerrado y el número de personas desempleadas ha aumentado hasta situarse en 44,1 millones.

- La cantidad considerable de empresas que han cerrado y de empleos que se han perdido, sumada al hecho de que los segmentos más vulnerables de la población se han llevado la peor parte de la crisis, ha llevado a que el número de personas en situación de pobreza pasara de 185,5 a 209 millones (del 30,3\% al 33,7\% de la población total). Por otra parte, el número de personas en situación de pobreza extrema aumentará hasta alcanzar los 78 millones: 8 millones más que antes. Además, la fuerte contracción de la inversión limitará la acumulación futura de capital, así como la capacidad de las economías de la región para generar crecimiento y empleo. Es probable que el desarrollo económico y social de la región sufra un retroceso de al menos un decenio. Hacia finales de 2020, el PIB per cápita era igual al de $2010^{5}$.

La información empleada para la elaboración de este documento, salvo que se indique otra cosa, es la disponible hasta el 1 de febrero de 2021.

Véase CEPAL (2020a). El cálculo de cuánto se contrajo la inversión, asi como la comparación de América Latina y el Caribe con otras regiones en desarrollo, se basan en FMI (2020a y 2021c).

Esto parece indicar que el ciclo de inversión en América Latina y el Caribe es más sensible a las fluctuaciones del PIB que el de cualquier otra región del mundo en desarrollo. Véase CEPAL (2017).

4 Las brechas estructurales se refieren a los obstáculos estructurales que frenan el crecimiento sostenido, equitativo e inclusivo de América Latina y el Caribe. La CEPAL ha identificado 12 brechas en materia de desigualdad y pobreza, endeudamiento, inversión y ahorro, productividad e innovación, infraestructura educación, salud, tributación, género y medio ambiente. Véase CEPAL (2012).

CEPAL (2020a).

\section{Índice}

Introducción

A. El impacto económico y social del COVID-19 ampliará de forma considerable la brecha de financiamiento de la región.

B. Para cerrar la brecha de financiamiento interna y externa es necesario que las instituciones financieras internacionales aumenten la disponibilidad de liquidez conforme a las necesidades de financiamiento de los países de América Latina y el Caribe.

C. Primera medida de política: ampliar y redistribuir la liquidez desde los países desarrollados hacia los países en desarrollo..

D. Segunda medida de política: centrarse en fortalecer la cooperación regional aumentando la capacidad de préstamo y respuesta de las instituciones financieras regionales, subregionales y nacionales, y estrechando sus vínculos con los bancos multilaterales de desarrollo.....9

E. Tercera medida de política: reforma institucional de la arquitectura de la deuda multilateral.

F. Cuarta medida de política: proporcionar a los países un conjunto de instrumentos innovadores destinados a aumentar la capacidad de reembolso de la deuda y evitar el endeudamiento excesivo...

G. Quinta medida de política: integrar las medidas de liquidez y de reducción de la deuda a una estrategia de financiamiento para el desarrollo encaminada a construir un futuro mejor

H. La crisis actual debe aprovecharse como una oportunidad para alcanzar un amplio consenso social y político que permita aplicar reformas ambiciosas con el fin de emprender un proceso de construcción sostenible e igualitario hacia el futuro..

Bibliografía . 
- Los efectos de la pandemia y las políticas aplicadas a modo de respuesta han aumentado las necesidades de liquidez de los países de la región para afrontar la fase de emergencia. Al mismo tiempo, estos factores han llevado a que se elevara el nivel de endeudamiento (América Latina y el Caribe es la región más endeudada del mundo en desarrollo), y eso puede poner en peligro la recuperación y la capacidad de los países para construir un futuro mejor.

- Las dificultades de América Latina y el Caribe son reflejo de la situación histórica de los países de ingreso medio, cuya ubicación en el sistema de cooperación internacional en lo que atañe al nivel de desarrollo social y económico se determina sobre la base del PIB per cápita ${ }^{6}$. Los países de ingreso medio a menudo se caracterizan por presentar un elevado nivel de desigualdad y algunas de las vulnerabilidades que se observan en los países de ingreso bajo; al mismo tiempo, son incapaces de crear las capacidades empresariales y sociales con una amplia base que les permitan ser objeto de un proceso de cambio estructural encaminado hacia la innovación y hacia una producción más intensiva en conocimiento, e impulsar la convergencia con las economías más avanzadas ${ }^{7}$

- En el contexto actual de la pandemia, la agenda de financiamiento para el desarrollo plantea dos retos interrelacionados. A corto plazo, se debe favorecer la expansión del gasto público en salud y prestar una atención especial a los grupos vulnerables, en particular a los segmentos de ingresos bajos y a las personas mayores ${ }^{8}$. Además, las políticas de financiamiento para el desarrollo a corto plazo también son necesarias para compensar los efectos perjudiciales que las políticas de contención, basadas en el distanciamiento físico y el aislamiento voluntario, tienen sobre la actividad económica, el tejido productivo (la estructura productiva) y el empleo.

- Esto supone sostener el consumo de las personas y las familias, para lo que es necesario adoptar medidas excepcionales transitorias de sostenimiento del ingreso, como una renta básica temporal garantizada por el Estado. Estas medidas deben tener el mayor alcance posible, ya que en la región hay estratos amplios de la población que son muy susceptibles de caer en la pobreza, a menudo debido a que perciben ingresos inestables y a que trabajan en el sector informal.

- A mediano y largo plazo, a medida que la prioridad de las políticas pase a ser construir un futuro mejor en lugar de hacer frente a la urgencia, el programa de financiamiento para el desarrollo debe promover una orientación de política anticíclica que tenga por objeto aumentar el empleo y mantener un crecimiento adecuado. En este contexto, la ampliación de los gastos públicos de capital y los desembolsos destinados a la transformación productiva y la ecologización de la economía son fundamentales para impulsar la labor de recuperación.

- En este informe se propone un conjunto de medidas de política destinadas a abordar ambos retos, y luego se pone énfasis en iniciativas que se podrían emprender para construir un futuro mejor.

- La primera medida de política consiste en afrontar el reto a corto plazo ampliando la liquidez y redistribuyéndola desde los países desarrollados hacia los países en desarrollo por medio de derechos especiales de giro (DEG). La redistribución de la liquidez también se puede poner en práctica mediante la creación de fondos multilaterales como el Fondo para Aliviar la Economía COVID-19 (FACE) que propuso el Gobierno de Costa Rica. La segunda medida de política se centra en fortalecer la cooperación regional aumentando la capacidad de préstamo y respuesta de los bancos de desarrollo regionales, subregionales y nacionales, así como la de otras instituciones regionales ${ }^{9}$

- El acceso a un mayor financiamiento debe complementarse con una tercera medida de política destinada a reformar la arquitectura de la deuda internacional. Esto supondría crear un mecanismo multilateral de reestructuración de la deuda y una agencia multilateral de calificación crediticia. También se debe ampliar el alcance de la Iniciativa de Suspensión del Servicio de la Deuda promovida por el Grupo de los 20 (G20) de modo que abarque a todas las partes interesadas pertinentes (es decir, el sector privado y las instituciones multilaterales) y a los países vulnerables de ingreso medio. Además, la iniciativa debe prolongarse más allá de 2021.

- En las estrategias para afrontar el problema de la deuda no se debe adoptar un enfoque único. Al igual que otras regiones en desarrollo, América Latina y el Caribe es heterogénea en cuanto a sus estructuras económicas y sociales. Las diferentes realidades (en lo que atañe al tamaño, la base productiva y las vulnerabilidades) exigirán elegir y calibrar con cuidado políticas e instrumentos que se adapten a las especificidades y necesidades de las subregiones o países concretos.

\footnotetext{
La CEPAL ha sostenido que es el enfoque de las brechas estructurales el que debe guiar la evaluación de las necesidades de desarrollo de los países, y la forma en que la cooperación internacional se organiza y asigna. Este enfoque se basa en el análisis de un conjunto de brechas estructurales cuya pertinencia puede variar según las especificidades de cada país. Véase CEPAL (2012). 
- La cuarta medida de política consiste en promover el mayor uso de diferentes instrumentos innovadores destinados a evitar el endeudamiento excesivo y a aumentar la capacidad de los países para afrontar el pago y servicio de la deuda. En los instrumentos innovadores se vincula la capacidad de reembolso de los países con la exposición y vulnerabilidad de estos frente a los desastres naturales (como se hace en el caso de las cláusulas sobre los huracanes) o a los altibajos del ciclo económico (como en los bonos vinculados al ingreso nacional o los instrumentos de deuda estatales contingentes para soberanos).

- La quinta medida de política consiste en entrelazar el mayor acceso a la liquidez y la reducción de la deuda con los objetivos de desarrollo a mediano y largo plazo y, por tanto, con las iniciativas encaminadas a construir un futuro mejor. En este sentido, la crisis actual también debe aprovecharse no solo como una oportunidad para repensar la agenda de financiamiento para el desarrollo de los países de ingreso medio, sino también como una ocasión para alcanzar un amplio consenso social y político destinado a implementar reformas ambiciosas con el fin de emprender un proceso de reconstrucción sostenible e igualitario. Construir un futuro mejor significa colocar la igualdad y la sostenibilidad medioambiental en el centro de la fase de recuperación.

\section{A. El impacto económico y social del COVID-19 ampliará de forma considerable la brecha de financiamiento de la región}

- La respuesta gubernamental a la emergencia, que se ha centrado en la salud pública y en las medidas de gasto social, junto con la drástica caída de los ingresos tributarios, ha aumentado el déficit fiscal y agravado la carga de la deuda, especialmente en las economías de menor tamaño, como los pequeños Estados insulares en desarrollo (PEID) del Caribe. Según los últimos datos disponibles, el gasto público en América Latina pasó de representar el 15,2\% del PIB de enero a septiembre de 2019 a representar el 18,1\% de este en el mismo período de 2020, lo que se explica sobre todo por el aumento de las transferencias corrientes ${ }^{10}$. En el caso del Caribe, el gasto público pasó del $12,8 \%$ al $14,8 \%$ del PIB en el mismo período.

- En todos los países, sin excepción, la situación fiscal se ha deteriorado y el nivel de endeudamiento del gobierno general ha aumentado ${ }^{11}$. En la actual situación, se espera que dicho endeudamiento se incremente del 68,9\% al 79,3\% del PIB entre 2019 y 2020 a nivel regional, lo que convierte a América Latina y el Caribe en la región más endeudada del mundo en desarrollo y la que tiene el mayor servicio de deuda externa en relación con las exportaciones de bienes y servicios (57\%) (véase el gráfico 1) $)^{12}$.

Gráfico 1 | Regiones en desarrollo: indicadores de deuda seleccionados, 2020 (En porcentajes)

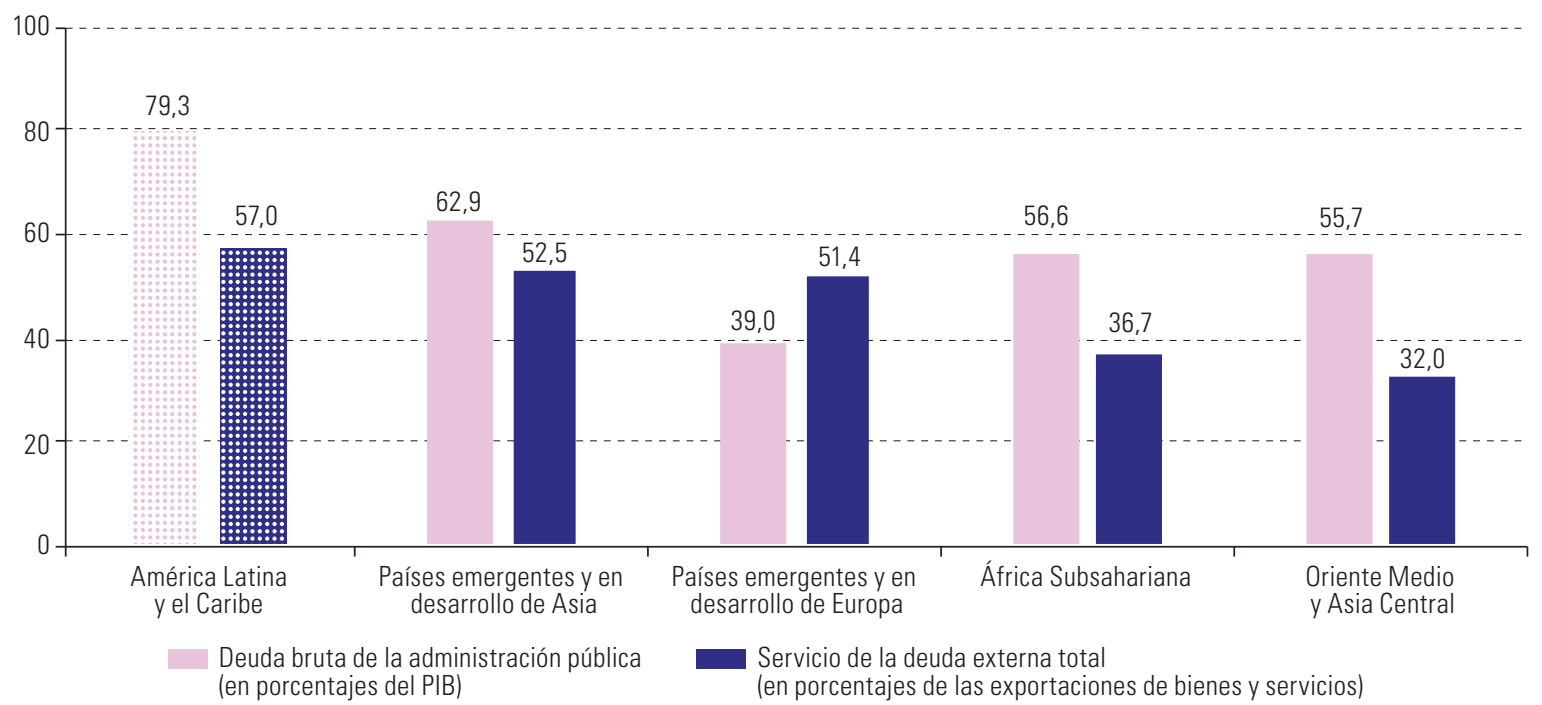

Fuente: Comisión Económica para América Latina y el Caribe (CEPAL), sobre la base de Fondo Monetario Internacional (FMI), World Economic Outlook Database, octubre de 2020 [en línea] https://www.imf.org/en/Publications/WEO/weo-database/2020/October.

\footnotetext{
${ }_{10}$ Las transferencias corrientes explican el $72 \%$ del aumento del gasto público en América Latina. Véase CEPAL (2020a).

11 El mayor aumento de la deuda del gobierno general se ha registrado en los PEID del Caribe, cuyo nivel de endeudamiento también se encuentra entre los más altos de la región. Véase FMI (2020a).

12 Se debe tener en cuenta que en las cifras agregadas de la región se pueden ocultar diferencias importantes entre los países.
} 
- El aumento generalizado del desequilibrio fiscal y el endeudamiento ha incrementado las necesidades de liquidez en todos los países de la región, a pesar de la considerable heterogeneidad que hay entre ellos en cuanto a la situación fiscal y a la vulnerabilidad de la deuda ${ }^{13}$. Esto impone una importante limitación a la respuesta de los gobiernos frente a la pandemia de COVID-19 y, a mediano plazo, socava la capacidad de estos para construir un futuro mejor.

- La brecha de financiamiento del sector público se agrava por la necesidad de apoyar la balanza de pagos, sobre todo en las economías más pequeñas de la región (los países de Centroamérica y el Caribe), debido a las interrupciones de la cadena de suministro y a la disminución de las exportaciones, en particular de la exportación de servicios (turismo). De 2019 a 2020, el déficit en cuenta corriente pasó del $1,4 \%$ al $4,5 \%$ del PIB en el istmo centroamericano y del $4,8 \%$ al $17,2 \%$ del PIB en el Caribe (véase el gráfico 2$)^{14}$. Además, en la región habrá una importante caída de la inversión extranjera directa (IED) que será de entre el $45 \%$ y el $55 \%$, aproximadamente, en el mismo período ${ }^{15}$.

Gráfico 2 | Istmo Centroamericano y el Caribe: balanza en cuenta corriente como porcentaje del PIB, 2019-2020 (En porcentajes)

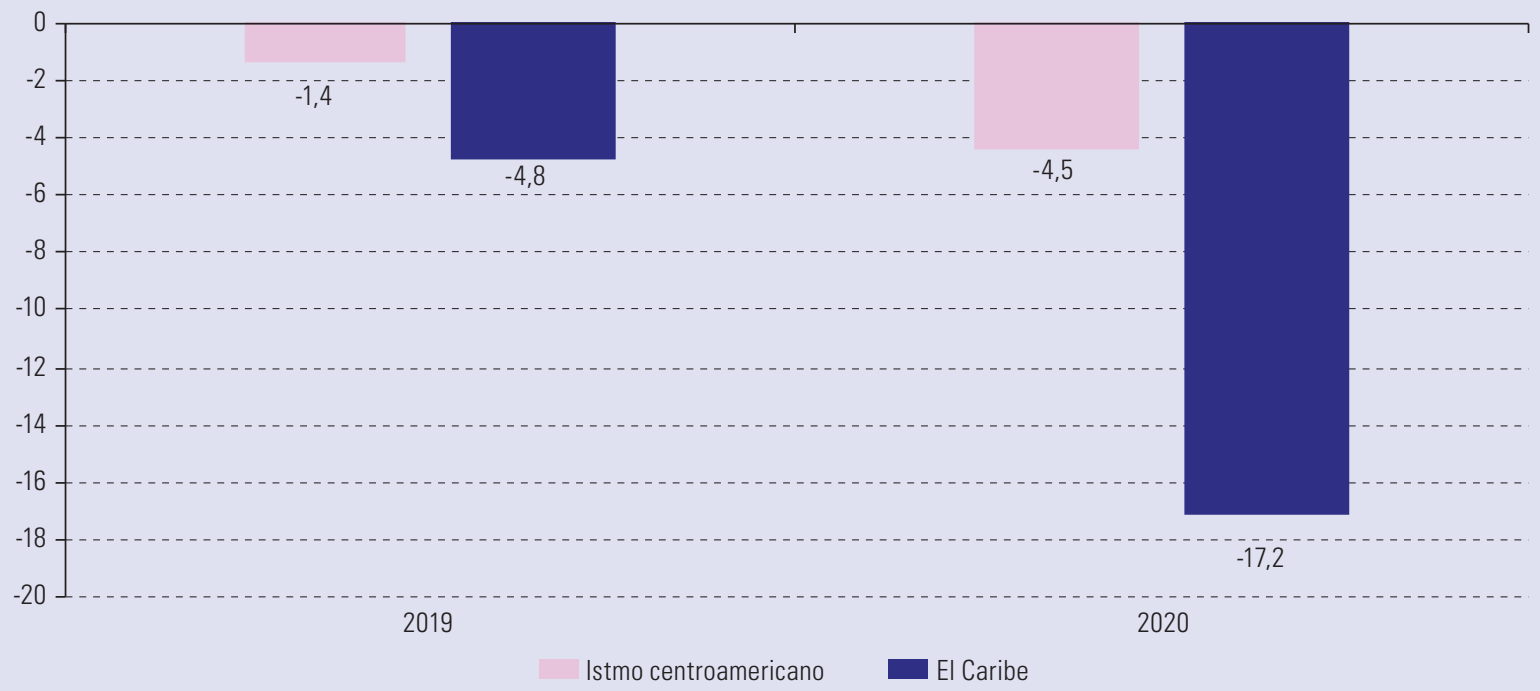

Fuente: Comisión Económica para América Latina y el Caribe (CEPAL), sobre la base de Fondo Monetario Internacional (FMI), World Economic Outlook Database, octubre de 2020 [en línea] https://www.imf.org/en/Publications/WEO/weo-database/2020/October.

\section{B. Para cerrar la brecha de financiamiento interna y externa es necesario que las instituciones financieras internacionales aumenten la disponibilidad de liquidez conforme a las necesidades de financiamiento de los países de América Latina y el Caribe}

- Las instituciones multilaterales han respondido rápidamente a las demandas de liquidez de los países en desarrollo, entre ellos los de América Latina y el Caribe, con una serie de iniciativas importantes que comparten objetivos similares: mitigar el impacto inmediato de la pandemia y financiar la recuperación económica. Dados los efectos sociales y económicos sin precedentes de la pandemia, estas iniciativas deben ampliarse para atender las necesidades de financiamiento de los países en toda su extensión. Se calcula que las necesidades globales de financiamiento de los países en desarrollo ascienden a 2,5 billones de dólares, lo que supera la capacidad de préstamo del Fondo Monetario Internacional (FMI) ${ }^{16}$.

\footnotetext{
13 En 2019, la deuda de las administraciones públicas iba del 122\% del PIB en Barbados al 26\% del PIB en el Paraguay. En 2020, dichas cifras iban de 145\% del PIB en Suriname al 32\% del PIB en Guatemala. En los datos correspondientes a 2019 se excluye la República Bolivariana de Venezuela.

14 En los datos que se brindan en este documento con relación al istmo centroamericano se incluyen la República Dominicana y Haití.

15 Los datos disponibles apuntan a que las entradas de IED se contrajeron un $45 \%$ en Centroamérica y un $27 \%$ en el Caribe en el segundo trimestre de 2020 (CEPAL, 2020b).

16 Se estima que la capacidad total de préstamo del FMI asciende a 1 billón de dólares. Sin embargo, un cálculo más preciso en que se tienen en cuenta los compromisos de préstamo de la institución, así como los recursos de las cuotas no utilizables y los saldos prudenciales, sitúa la capacidad de préstamo en unos 800.000 millones de dólares. La cifra de 2,5 billones de dólares se calculó en marzo de 2020 y es probable que haya aumentado desde entonces (FMI, 2020b).
} 
- El FMI ha puesto a disposición de 21 países de América Latina y el Caribe (8 del Caribe, 7 del istmo centroamericano y 6 de América del Sur) la mayor parte de sus préstamos de emergencia relacionados con el COVID-19. En enero de 2021, dicha institución había destinado unos 66.500 millones de dólares a América Latina y el Caribe, lo que representaba un 63\% del desembolso total (106.000 millones de dólares) que había destinado a 85 economías en desarrollo, (véase el gráfico 3) ${ }^{17}$.

Gráfico 3 | Distribución de los préstamos de emergencia del Fondo Monetario Internacional por región de países en desarrollo, enero de 2021

(En porcentajes)

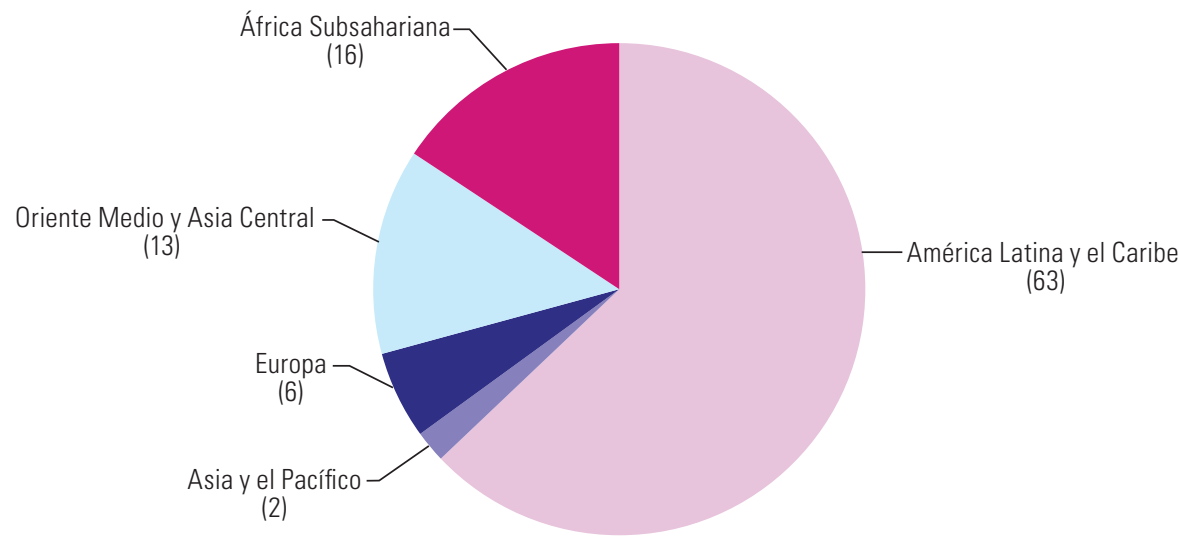

Fuente: Comisión Económica para América Latina y el Caribe (CEPAL), sobre la base de Fondo Monetario Internacional (FMI), “COVID-19 Financial Assistance and Debt Service Relief", 2021 [en línea] https://www.imf.org/en/Topics/imf-and-covid19/COVID-Lending-Tracker.

- Los préstamos se conceden a través de instrumentos financieros que tienen una condicionalidad limitada o nula con el fin de aumentar la flexibilidad y la capacidad de respuesta del FMI para hacer frente a los efectos de la pandemia. La racionalización de la condicionalidad también fue una característica clave de los préstamos que el FMI concedió durante la crisis financiera mundial de 2008-2009.

- Los principales instrumentos financieros del FMI que se han utilizado en los países de América Latina y el Caribe son el Servicio de Crédito Rápido (SCR), el Instrumento de Financiamiento Rápido (IFR) (75\% del total) y, en menor medida, la Línea de Crédito Flexible (LCF) ${ }^{18}$.

- EI SCR se ofrece con una tasa de interés del $0 \%$, un período de gracia de 5,5 años y un vencimiento de 10 años. En el IFR se cobran tasas de interés inferiores a las del mercado (la tasa de interés correspondiente a los DEG más un margen fijo que el Directorio Ejecutivo del FMI determina de forma anual), y se ofrece un período de pago que va de 3,25 a 5 años ${ }^{19}$. Por último, la LCF también se concede a un costo similar, y se puede renovar al cabo de uno o dos años. En el caso de los dos primeros instrumentos, los países pueden pedir prestado hasta el $100 \%$ de la cuota que tienen en el FMI. Los préstamos que se otorgan en el marco de la LCF, en cambio, no están limitados por la cuota del país y, de hecho, no hay límite para los recursos del FMI que se pueden prestar $^{20}$.

- Estos instrumentos financieros no benefician a todos los países por igual. Los que tienen sólidos fundamentos económicos, como Chile, Colombia y el Perú, pueden acceder al financiamiento sin límites de cuota (a través de la LCF) ${ }^{21}$. No obstante, esta no es una opción que esté disponible para la mayoría de los países, en particular para los PEID del Caribe.

- En algunos países del Caribe se enfrentan desequilibrios fiscales y externos recurrentes debido, en parte, a su pequeñez, a las limitaciones estructurales, y a la elevada exposición y vulnerabilidad frente a los riesgos naturales. Esto limita en gran medida la posibilidad de lograr los sólidos

17 En esta cifra no se incluye el financiamiento por un monto de 488,7 millones de dólares que se proporcionó a través del alivio del servicio de la deuda otorgado por el Fondo Fiduciario para Alivio y Contención de Catástrofes (CCRT). En enero de 2021, los compromisos de préstamo del FMI ascendían a 267.000 millones de dólares (FMI, 2021a). Haiti es el único país de América Latina y el Caribe que, por ser de ingreso bajo, también reúne las condiciones para recibir alivio de la deuda en el marco del Fondo Fiduciario para Alivio y Contención de Catástrofes (FFACC). Entre marzo y octubre de 2020, al país le aprobaron 11,2 millones de dólares en dicho marco.

18 Otros instrumentos financieros que se han utilizado en una escala mucho menor son los siguientes: el Servicio Ampliado del Fondo (SAF), que se usó en Barbados y el Ecuador, y del cual Costa Rica también hace uso; la Línea de Precaución y Liquidez (LPL), que se empleó en Panamá, y el acuerdo de derecho de giro y el Servicio de Crédito Stand-By (SCS), que se utilizaron en Honduras. A diferencia de los instrumentos de financiamiento de emergencia relacionados con el COVID-19, las condiciones de préstamo en el marco del SAF y del acuerdo de derecho de giro implican cumplir la condicionalidad del FMI.

19 El costo del préstamo también incluye un recargo que varía en función del importe y del tiempo que el crédito esté pendiente.

20 Véase FMI(2020c). Como lo explica el FMI, en el caso de la LCF, la necesidad de recursos se evalúa caso por caso en función de las necesidades reales o potenciales de la balanza de pagos del país miembro. La LCF se creó en 2009 para aumentar la flexibilidad de los préstamos del FMI y racionalizar las condiciones que se imponían, con el fin de mejorar la capacidad de respuesta de la institución a la crisis financiera mundial. Véase FMI (2009).

${ }^{21}$ México también tiene acceso a una LCF. En el caso de este país, la línea se aprobó en noviembre de 2019, antes de la pandemia, y asciende a unos 61.000 millones de dólares (FMI, 2020d). 
antecedentes de desempeño económico que se exigen en la LCF22. Los datos disponibles sobre los PEID del Caribe señalan que, antes de la pandemia, en el período 2015-2019, el déficit combinado en cuenta corriente promediaba el 6,9\% del PIB. En las economías pertenecientes a la Organización de Estados del Caribe Oriental (OECO), el desequilibrio exterior era mucho mayor $(9,4 \% \text { del PIB en el mismo período })^{23}$. En algunos casos, estos grandes desequilibrios externos están asociados a coeficientes elevados de endeudamiento.

- Los datos disponibles de los países de América Latina y el Caribe señalan que el financiamiento que se otorgó en el marco del IFR y el SCR solo cubrió el 32,3\% y el 23,1\% en promedio, respectivamente, de las necesidades de financiamiento internas y externas que los países tenían en $2020^{24}$. Esto equivalía al $0,8 \%$ y al $2,1 \%$ del PIB, y al $6,5 \%$ y al $8,0 \%$ de las reservas internacionales, respectivamente (véase el gráfico 4). Además de los servicios de préstamo de emergencia del FMI, en los países hay otras tres alternativas para acceder al financiamiento: postularse para un programa estándar del FMI y cumplir con las condicionalidades asociadas; solicitar préstamos a los bancos multilaterales de desarrollo, o recurrir al mercado internacional de bonos. El orden jerárquico de estas alternativas de financiamiento no es una cuestión resuelta. Según Standard \& Poor's (2020, pág. 4), los bancos multilaterales de desarrollo son prestamistas de última instancia y deberían entrar en escena cuando el acceso al financiamiento comercial es limitado.

Gráfico 4 | América Latina y el Caribe (países seleccionados): cobertura del déficit de financiamiento proporcionada por el Instrumento de Financiamiento Rápido y el Servicio de Crédito Rápido, 2020a (En porcentajes del PIB y de las reservas internacionales)

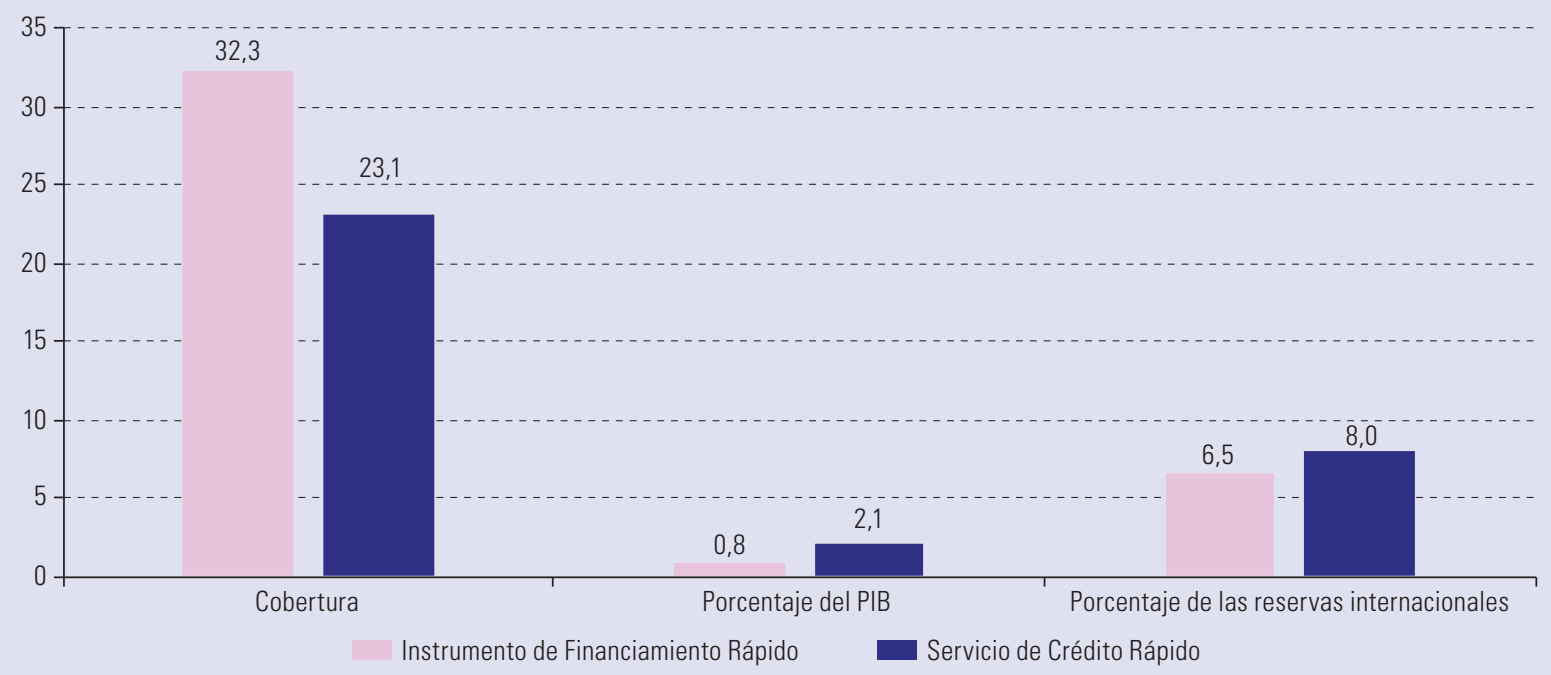

Fuente: Comisión Económica para América Latina y el Caribe (CEPAL), sobre la base de información del Fondo Monetario Internacional (FMI) e información oficial, 2020.

a Las cifras son cálculos que se basan en una serie de informes del FMI sobre los países de América Latina y el Caribe que solicitaron financiamiento de emergencia a través del Instrumento de Financiamiento Rápido o del Servicio de Crédito Rápido en 2020. Estos países son los siguientes: Bahamas, Bolivia (Estado Plurinacional de), Costa Rica, Dominica, Ecuador, El Salvador, Granada, Guatemala, Haití, Jamaica, Panamá, Paraguay, República Dominicana, San Vicente y las Granadinas, y Santa Lucía.

\section{Primera medida de política: ampliar y redistribuir la liquidez desde los países desarrollados hacia los países en desarrollo}

\section{La manera más rápida, eficiente y económica de aumentar la liquidez es llevar a cabo una emisión masiva de DEG y, a corto plazo, reasignar de forma voluntaria los DEG no utilizados de modo que la liquidez se reoriente desde los países desarrollados hacia los países en desarrollo}

- Los fondos adicionales destinados a cubrir la brecha de financiamiento deberían proporcionarse ampliando los servicios de crédito existentes, como los DEG, que son activos internacionales de reserva creados por el FMI para complementar las reservas oficiales de sus países miembros. Los DEG constituyen un activo potencial frente a las monedas de libre uso de los miembros

22 Véase FMI (2020c).

23 Los paises que pertenecen a la OECO son Antigua y Barbuda, Dominica, Granada, Saint Kitts y Nevis, San Vicente y las Granadinas y Santa Lucia. El resto de los países del Caribe son las Bahamas, Belice, Guyana, Jamaica, Suriname y Trinidad y Tabago.

24 La cobertura se refiere a las necesidades de financiamiento internas y externas que el FMI calcula al conceder el Instrumento de Financiamiento Rápido o el SCR. 
del FMI. Las asignaciones se realizan de forma proporcional a la participación (cuota asignada) de cada Estado miembro en el FMI. A finales de febrero de 2021, las asignaciones acumuladas ascendían a 204.200 millones de DEG, lo que equivalía a unos 282.700 millones de dólares. En esta cifra estaban incluidos los 182.600 millones de DEG que se asignaron en 2009 como parte de las medidas destinadas a proporcionar liquidez durante la crisis financiera mundial. A principios de marzo de 2021, el G20 aprobó una nueva emisión de DEG por parte del FMI, cuyo monto todavía está por determinarse.

- Una nueva emisión de DEG aumentaría la liquidez de los países sin generar más deuda ${ }^{25}$. A las economías en desarrollo se les asignaría aproximadamente un $40 \%$ de la nueva emisión, y el resto iría a los países desarrollados. América Latina y el Caribe recibiría aproximadamente un $7,6 \%$ de la emisión (véase el gráfico 5).

Gráfico 5 || Asignación de los derechos especiales de giro del Fondo Monetario Internacional por región, diciembre de 2020 (En porcentajes)

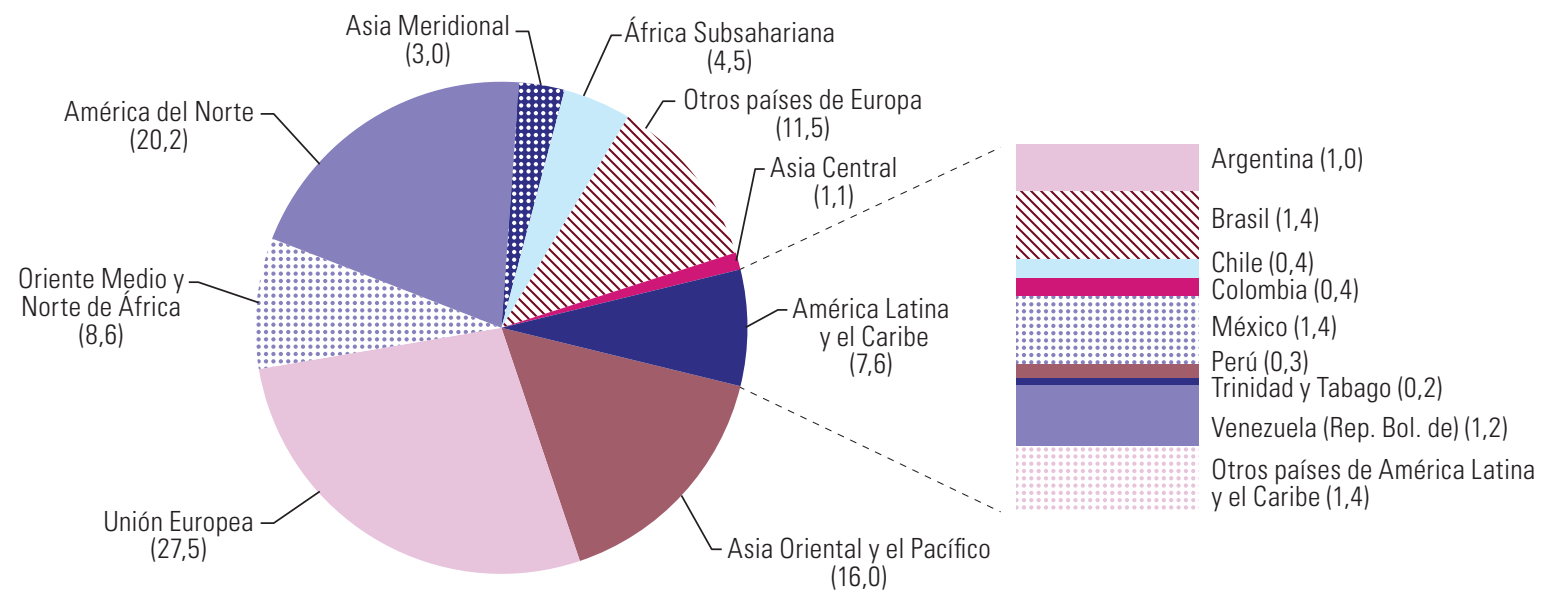

Fuente: Comisión Económica para América Latina y el Caribe (CEPAL), sobre la base de Fondo Monetario Internacional (FMI), “IMF Members’ Quotas and Voting Power, and IMF Board of Governors" 2020 [en línea] https://www.imf.org/external/np/sec/memdir/members.aspx.

- Si se emitieran y asignaran 500.000 millones de DEG nuevos, ello representaría 56.000 millones de dólares de reservas internacionales adicionales para las economías de América Latina y el Caribe ${ }^{26}$.

- América del Sur recibiría 36.700 millones de dólares; México, 13.200; el istmo centroamericano, 3.600, y el Caribe, 2.500, cifras que representarían un $66 \%$, un $24 \%$, un $7 \%$ y un $4 \%$ del total, respectivamente. Una nueva emisión de DEG beneficiaría a algunos de los países más endeudados de la región (entre ellos, la Argentina, Belice, el Ecuador y Suriname) en cuanto a la contribución de los DEG a la acumulación de reservas internacionales (véase el cuadro 1).

- Para que se puedan emitir nuevos DEG se requiere la aprobación del $85 \%$ de los votos de los países miembros del FMI y, por tanto, necesariamente la de los Estados Unidos, que posee el $16,5 \%$ de los votos de la Junta de Gobernadores del FMI ${ }^{27}$.

- Determinados obstáculos políticos han impedido llevar a cabo una nueva emisión de DEG. Mientras esta no se realice, la liquidez también podría aumentarse mediante una reasignación voluntaria de los DEG no utilizados que ya existen (DEG que superan la asignación del país) desde los países desarrollados hacia los países en desarrollo. Los países de ingreso alto poseen aproximadamente 190.000 millones de dólares en DEG, que podrían reasignarse a los países en desarrollo.

- Para reasignar los DEG sería necesario resolver algunos problemas importantes. Si bien cada país tiene derecho a transferir sus DEG a otro de forma voluntaria, mancomunar los DEG utilizando la arquitectura multilateral existente sería una forma más eficaz de hacer frente a las necesidades de liquidez de los países en desarrollo, entre ellos los de América Latina y el Caribe. Además de que un conjunto de países de ingreso alto deberían aceptar ceder voluntariamente sus DEG, habría que llegar a un acuerdo en lo que concierne al mecanismo de reasignación. Esto podría implicar tener que decidir a qué conjunto de países beneficiar, y establecer las condiciones y los criterios de préstamo correspondientes.

\footnotetext{
25 Además, las tasas de interés cobradas por el uso de los DEG son muy bajas, lo que beneficia a los países con una prima de riesgo elevada.

${ }^{26}$ El 5 de febrero de 2021, el tipo de cambio del DEG respecto del dólar estadounidense era 1,433250 (FMI, 2021b).

27 Con la aprobación del Departamento del Tesoro de los Estados Unidos, el FMI puede emitir hasta 649.000 millones de DEG sin necesidad de que el Congreso de dicho país lo apruebe.
} 
Cuadro 1 | América Latina y el Caribe (30 países): asignación de una emisión hipotética de 500.000 millones de derechos especiales de giro por subregión y país

(En porcentajes de las reservas internacionales brutas a valores de 2020)

\begin{tabular}{|c|c|c|c|c|c|}
\hline \multirow{2}{*}{$\begin{array}{l}\text { El Caribe } \\
\text { País } \\
\end{array}$} & & \multicolumn{2}{|l|}{ América del Sur } & \multicolumn{2}{|l|}{ Istmo centroamericano } \\
\hline & & País & & País & \\
\hline Antigua y Barbuda & 10,5 & Argentina & 12,0 & Costa Rica & 7,3 \\
\hline Bahamas & 13,5 & Bolivia (Estado Plurinacional de) & 6,1 & El Salvador & 10,8 \\
\hline Barbados & 14,2 & Brasil & 4,7 & Guatemala & 3,7 \\
\hline Belice & 21,3 & Chile & 6,9 & Honduras & 4,7 \\
\hline Dominica & 8,3 & Colombia & 5,4 & Nicaragua & 13,3 \\
\hline Granada & 6,8 & Ecuador & 31,4 & Panamá & 7,4 \\
\hline Guyana & 44,4 & Paraguay & 3,2 & República Dominicana & 6,8 \\
\hline Haití & 15,6 & Perú & 2,7 & & \\
\hline Jamaica & 15,5 & Uruguay & 4,0 & & \\
\hline Saint Kitts y Nevis & 5,5 & & & & \\
\hline Santa Lucía & 5,4 & & & & \\
\hline San Vicente y las Granadinas & 13,5 & & & & \\
\hline Suriname & 39,2 & & & & \\
\hline Trinidad y Tabago & 9,9 & & & & \\
\hline Promedio & 16,0 & & 8,5 & & 7,7 \\
\hline Mediana & 13,5 & & 5,4 & & 7,3 \\
\hline Desviación estándar & 11,8 & & 9,0 & & 3,3 \\
\hline
\end{tabular}

Fuente: Comisión Económica para América Latina y el Caribe (CEPAL), sobre la base de Fondo Monetario Internacional (FMI), "IMF Members' Quotas and Voting Power, and IMF Board of Governors", 2020 [en línea] https://www.imf.org/external/np/sec/memdir/members.aspx.

- A nivel regional, sería importante pensar en crear un nuevo fondo fiduciario por el que los países que tuvieran DEG sin utilizar pudieran destinar voluntaria o temporalmente parte de ellos a reforzar la capacidad financiera de los acuerdos financieros regionales y otras instituciones financieras de la región (bancos regionales de desarrollo). Este mecanismo de reasignación podría aplicarse tanto a los DEG recién emitidos como a las asignaciones anteriores.

\section{La creación de fondos multilaterales es otro mecanismo para redistribuir la liquidez desde las economías desarrolladas hacia las economías en desarrollo}

- Además de reasignar los DEG, una política complementaria que se podría aplicar para redistribuir la liquidez desde los países desarrollados hacia los países en desarrollo son los fondos de liquidez financiados por los primeros. Estos fondos pueden otorgar a las economías en desarrollo una participación mayor en el proceso de decisión sobre qué países serán los destinatarios y conforme a qué condiciones se reasignará la liquidez. Un ejemplo de fondo multilateral es la propuesta de Fondo para Aliviar la Economía COVID-19 (FACE).

- EI FACE tiene por objeto proporcionar un financiamiento extraordinario a los países en desarrollo, entre ellos los de ingreso bajo y medio, para mitigar el impacto social y económico que la pandemia ha tenido en los hogares y los sectores productivos. También se prevé financiar la recuperación económica una vez superada la pandemia.

- La propuesta es financiar este fondo con recursos de las economías desarrolladas y canalizarlos a través de los bancos multilaterales de desarrollo. El fondo constaría de 516.000 millones de dólares (un 3\% del PIB de los países de ingreso bajo y medio o el 0,7\% del PIB de los países desarrollados) que se destinarían a préstamos concesionales con un plazo de 50 años, un período de gracia de 5 años y una tasa de interés equivalente al $0 \%$ o a la tasa LIBOR actual $(0,7 \%)^{28}$. A los préstamos concesionales no se les imponen condiciones fiscales, monetarias ni estructurales ${ }^{29}$.

- Si los recursos del FACE se distribuyeran a las regiones en desarrollo sobre la base de los mismos criterios que se aplican para calcular el tamaño del fondo (el $3 \%$ del PIB de los países en desarrollo), América Latina y el Caribe podría recibir hasta el $12 \%$ de los fondos (60.000 millones de dólares), lo que sería ligeramente inferior al financiamiento que el FMI proporciona en la actualidad (véase el gráfico 6).

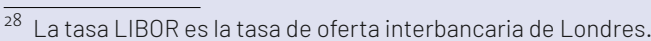

${ }^{29}$ CEPAL/Misión Permanente de Costa Rica ante las Naciones Unidas (2020). 
Gráfico 6 || Asignación hipotética de los recursos del Fondo para Aliviar la Economía COVID-19 (FACE) en función del criterio del $3 \%$ del PIB de las regiones en desarrollo

(En porcentajes)

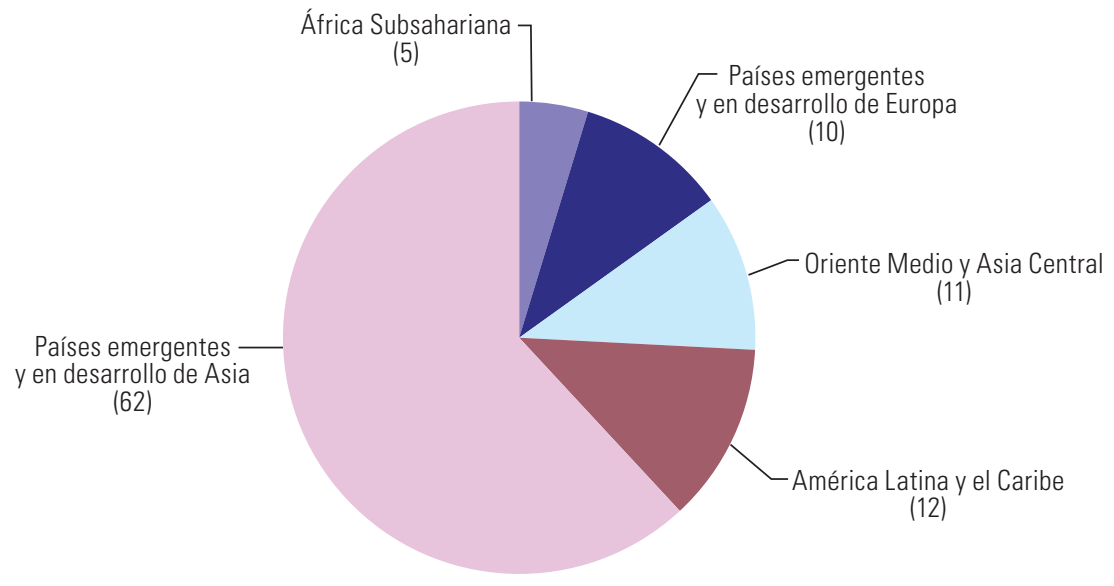

Fuente: Comisión Económica para América Latina y el Caribe (CEPAL), sobre la base de Fondo Monetario Internacional (FMI), World Economic Outlook Database, 2021 [en línea] http://www.imf.org/external/ns/cs.aspx?id=28.

\section{Segunda medida de política: centrarse en fortalecer la cooperación regional aumentando la capacidad de préstamo y respuesta de las instituciones financieras regionales, subregionales y nacionales, y estrechando sus vínculos con los bancos multilaterales de desarrollo}

- El Banco Interamericano de Desarrollo (BID) y los bancos de desarrollo subregionales -el Banco de Desarrollo de América Latina (CAF), el Banco Centroamericano de Integración Económica (BCIE) y el Banco de Desarrollo del Caribe (CARIBANK) - han destinado alrededor de 8.000 y 12.000 millones de dólares, respectivamente, a la lucha contra la pandemia ${ }^{30}$. En total, estas cifras representan el $0,5 \%$ del PIB y el 1,9\% de las exportaciones de bienes y servicios de la región. Estos fondos se utilizan para financiar programas de emergencia que comprenden medidas sanitarias, así como el otorgamiento de líneas de crédito contingente. En el caso del BID, la expansión de los préstamos para hacer frente a los efectos del COVID-19 en la región de hecho supera la que tuvo lugar tras la crisis financiera mundial de 2008-2009.

- Por su parte, los bancos nacionales de desarrollo han destinado el equivalente a 90.000 millones de dólares al apoyo financiero, lo que supera ampliamente lo aportado por los bancos de desarrollo regionales y subregionales (véase el gráfico 7). Además, los bancos nacionales también han proporcionado apoyo de la liquidez por medio de diversos instrumentos, como las garantías, las subvenciones y los planes de refinanciamiento (véase el gráfico 8). El importante rol que han asumido los bancos nacionales de desarrollo como actores clave en el suministro de financiamiento señala la necesidad de fomentar la cooperación y la coordinación entre los bancos de desarrollo regionales, subregionales y nacionales ${ }^{31}$.

- La capacidad de préstamo de los bancos de desarrollo puede incrementarse por dos medios diferentes: aumentando la capitalización, y flexibilizando los criterios de préstamo. EI BCIE aumentó el capital autorizado un 40\% (2.000 millones de dólares) en abril de 2020, y el BID está considerando la posibilidad de aumentar el capital de modo que los préstamos anuales puedan llegar a casi 20.000 millones de dólares (Martin, 2021).

\footnotetext{
30 En 2020, el CAF, el BCIE y el CARIBANK destinaron 10.000, 1.960 y 200 millones de dólares, respectivamente. Estos cálculos se basan en información oficial de las respectivas instituciones, en recortes de prensa y en FMI (2021b). La respuesta del Grupo BID a la pandemia consistió en un total de 8.076 millones de dólares y se centró en el financiamiento destinado a satisfacer necesidades inmediatas de salud pública, brindar redes de seguridad a las poblaciones vulnerables, fomentar la productividad económica y el empleo, y apoyar la implementación de medidas fiscales para ayudar a mitigar los efectos económicos.

31 También es necesario que los bancos multilaterales de desarrollo se coordinen. La coordinación de los bancos de desarrollo evitaría la duplicación de tareas y ampliaría la movilización del financiamiento privado, lo que aumentaría la eficiencia de las operaciones. Véanse los beneficios de la coordinación entre los bancos multilaterales de desarrollo en Bisogno y Fleiss (2020).
} 
Gráfico 7 | América Latina y el Caribe (países y agrupaciones seleccionados): importes que destinaron los bancos de desarrollo nacionales y los regionales o multilaterales a la respuesta frente al COVID-19, a febrero de $2021^{\text {a }}$ (En miles de millones de dólares)

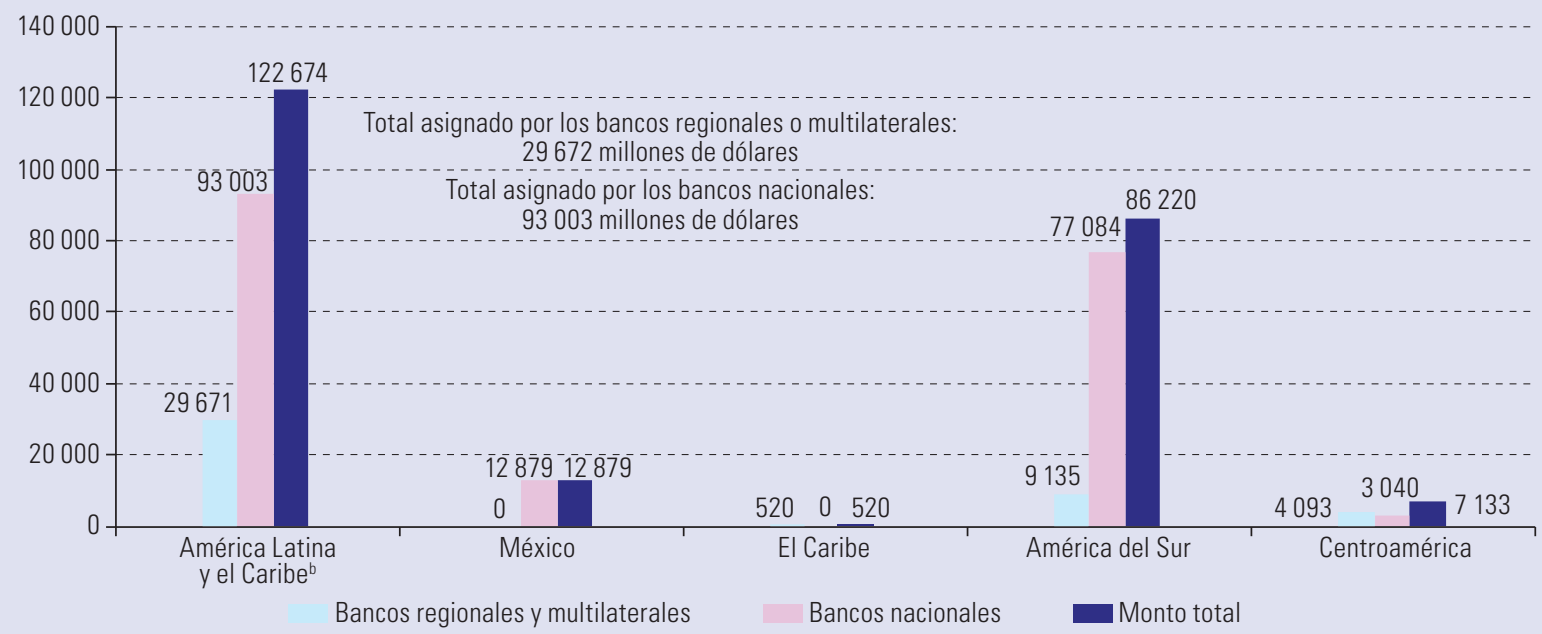

Fuente: Comisión Económica para América Latina y el Caribe (CEPAL), sobre la base de información oficial y reseñas de prensa.

a Bancos regionales y multilaterales: Banco Mundial, Banco Centroamericano de Integración Económica (BCIE), Banco Interamericano de Desarrollo (BID), Banco de Desarrollo de América Latina (CAF), Banco de Desarrollo del Caribe (CARIBANK), Fondo Monetario Internacional (FMI) y FONPLATA Banco de Desarrollo. Instituciones bancarias nacionales: Agencia Financiera de Desarrollo de Paraguay (AFDP), Agência de Fomento do Estado do Amazonas (AFEAM), Agência do Fomento do Rio Grande do Norte SA (AGN), Agência de Fomento do Estado de Santa Catarina SA (BADESC), Agência Estadual de Fomento (AgeRio), Agência de Fomento do Estado do Tocantins, Agencia Nacional de Desarrollo (ANDE) (Uruguay), Associação Brasileira de Desenvolvimento (ABDE), Banco Agrario de Colombia, Banco Ciudad (Argentina y Panamá), Banco da Amazônia, Banco de Brasilia (BRB), Banco de Desarrollo Agropecuario (Panama), Banco de Desenvolvimento de Minas Gerais (BDMG), Banco de Desarrollo del Ecuador, Banco de Desenvolvimento do Estado do Espírito Santo (BANDES), Banco de la Pampa (BLP) (Argentina), Banco do Brasil (BB), Banco do Nordeste (BNB), Caixa Econômica Federal (CEF), Banco Estado (Chile), Banco Hondureño de la Producción y la Vivienda (BANHPROVI) (Honduras), Banco Nación (Argentina), Banco Nacional de Desenvolvimento Econômico e Social (BNDES), Banco Popular y de Desarrollo Comunal (Costa Rica), Banco Provincia (Argentina) Banco Regional de Desenvolvimento do Extremo Sul (BRDE), Banco de Comercio Exterior (Bancoldex) (Colombia), Financiera de Desarrollo Territorial (FINDETER) (Colombia), Banco Cooperativo do Brasil (BANCOOB), Banco Cooperativo Sicredi (Brasil), Cresol (Brasil), Bancor (Argentina), Banco de Desarrollo de El Salvador (BANDESAL), BanEcuador, Corporación Financiera Nacional (CFN) (Ecuador), Instituto Ecuatoriano de Seguridad Social (IESS), Banco de la Seguridad Social (BIESS) (Ecuador), Banco de Desarrollo del Ecuador (BDE), Corporación Nacional de Finanzas Populares y Solidarias (CONAFIPS) (Ecuador), Banco Nacional de Obras y Servicios Públicos (BANOBRAS) (México), Nacional Financiera (México) (NAFIN), Banco Nacional de Comercio Exterior (BANCOMEXT) (México), Sociedad Hipotecaria Federal (México), Banco do Estado do Pará (Banpará), Banco de Reservas de la República Dominicana (BANRESERVAS), Banco de Desarrollo Rural (BANRURAL) (Guatemala), Banco de Desarrollo Productivo de Bolivia (BDP), Banco BICE (Argentina), Banco Nacional de Bolivia (BNB), Banco Nacional de Fomento (BNF) (Paraguay), Banco de la República Oriental del Uruguay (BROU), Caja de Ahorros (Panamá), Corporación Financiera de Desarrollo (COFIDE) (Perú), Corporación de Fomento de la Producción (CORFO) (Chile), Desenvolve - Agência de Fomento de Alagoas, Desenvolve - Agência de Fomento do Mato Grosso, Desenvolve - Agência de Fomento do São Paulo, Fondo para el Financiamiento del Sector Agropecuario (FINAGRO) (Colombia), Financiera Nacional de Desarrollo Agropecuario, Rural, Forestal y Pesquero (FND,) (México), Fideicomiso Instituido en Relación con la Agricultura (FIRA) (México), Fondo de Garantía para Pequeños Empresarios (FOGAPE) (Chile), Garantías Corfo para Inversión y Capital de Trabajo (FOGAIN) (Chile), Fondo de Garantías Buenos Aires (FOGABA), Banco Provincia (Argentina), GoiásFomento, Instituto Nacional de Desarrollo Agropecuario (INDAP) (Chile), Instituto Nacional de Fomento Cooperativo (INFOCOOP) (Costa Rica), Instituto para el Desarrollo de Antioquia (IDEA) (Costa Rica), Sistema de Banca para el Desarrollo (SBD) (Costa Rica), Sistema Nacional de Garantías para Empresas (SiGa) (Uruguay), Promotora de Comercio Exterior (Procomer) (Costa Rica), Instituto Nacional de Aprendizaje (INA) (Costa Rica) y Sociedad Hipotecaria Federal (SHF) (México).

b El monto total de América Latina y el Caribe, además de incluir los montos que cada país recibió de la banca nacional y de la banca regional y multilateral, abarca también 6.266 millones de dólares correspondientes a paquetes conjuntos regionales de la banca regional y multilateral (el FMl y el CAF) y 9.677 millones de dólares adicionales correspondientes a la actualización de montos informados por el BID y el CAF en febrero de 2021, sin desagregar los datos por país.

Gráfico 8 | Apoyo prestado por los bancos nacionales de desarrollo para hacer frente a los efectos del COVID-19, por tipo de instrumento, 2020

(En millones de dólares y en porcentajes del total)

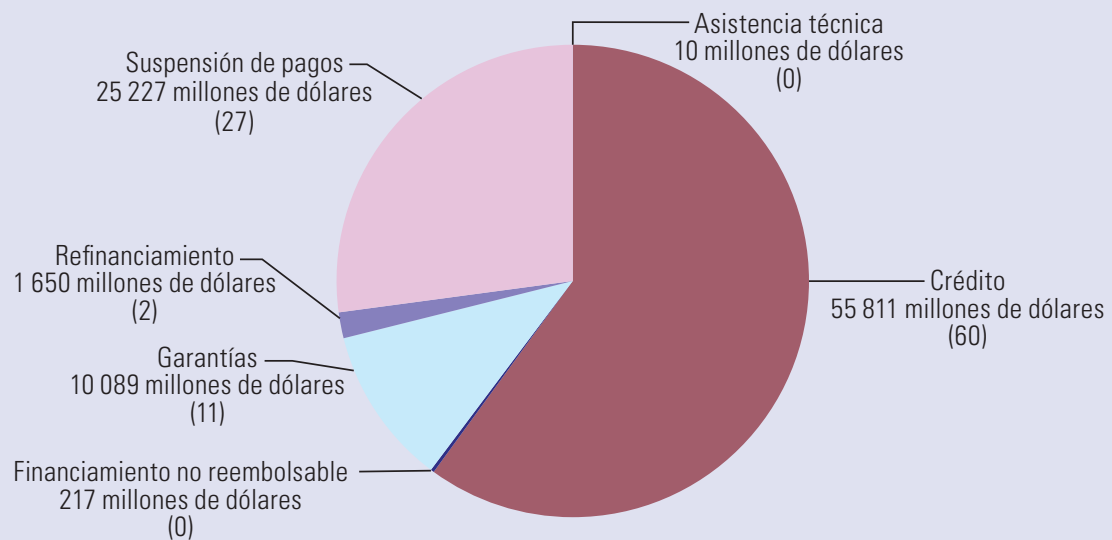

Fuente: Comisión Económica para América Latina y el Caribe (CEPAL), sobre la base de información oficial. 
- En el BID, al igual que en el Banco Mundial, también se podría utilizar el capital disponible de forma más eficaz reduciendo la relación entre los fondos propios y los préstamos hasta situarla en un nivel acorde con el de los bancos comerciales. En los bancos multilaterales de desarrollo se adopta una postura conservadora en cuanto al nivel de recursos propios: en los principales bancos de este tipo, la relación entre los fondos propios y los préstamos oscila entre el $20 \%$ y el $60 \%$, relación que es superior a la de la mayoría de los bancos comerciales (10\%-15\%) (Humphrey, 2020)32. En otras palabras, los bancos multilaterales de desarrollo tienen de 2 a 6 dólares de recursos propios por cada 10 dólares de préstamos pendientes, mientras que los bancos comerciales solo tienen de 1 a 1,50 dólares por cada 10 dólares de préstamos pendientes. Actualmente, la relación entre los fondos propios y los préstamos del Banco Mundial y del BID es de un 22,6\% y un $38,2 \%$, respectivamente.

- Otras instituciones, como el Fondo Latinoamericano de Reserva (FLAR), también son un componente importante de la red de cooperación regional. En respuesta a la crisis del COVID-19, el potencial del FLAR para otorgar préstamos a sus países miembros se aumentó en un $60 \%$ hasta alcanzar un total de 6.800 millones de dólares. Asimismo, en la institución se estableció una línea de crédito excepcional de hasta cinco años, con un período de gracia de tres, para que en los países miembros se pudiera hacer frente a las dificultades que el COVID-19 causó en la balanza de pagos (FLAR, 2020).

\section{E. Tercera medida de política: reforma institucional de la arquitectura de la deuda multilateral}

\section{El aumento de la deuda es un escollo importante a la hora de dar una respuesta eficaz a la urgencia provocada por la pandemia y de lograr una recuperación sostenible}

- En las circunstancias actuales, los problemas de liquidez que aquejan a los países en desarrollo, en particular a los de América Latina y el Caribe, pueden menoscabar la capacidad de los países para responder a la pandemia y construir un futuro mejor. En un contexto de crecimiento escaso, en algunos países los problemas de liquidez también pueden convertirse en un problema de solvencia que amenace tanto al sector privado como al público.

- En el caso del sector privado, la falta de solvencia puede ocasionar un aumento de la morosidad, las quiebras y las pérdidas del sector financiero que ponga en peligro la estabilidad financiera. En el caso del sector público, los problemas de solvencia pueden llevar a que se apliquen políticas de austeridad que pueden agravar la recesión económica y, por tanto, la acumulación de deuda. La mayoría de las economías de América Latina y el Caribe se han comprometido, de una manera u otra, a aplicar políticas de reducción del déficit.

- Dada la importancia de los países de ingreso medio en la economía mundial, la ausencia de alternativas para abordar el problema de la deuda puede poner en peligro no solo la recuperación, sino también la estabilidad financiera mundial. Los países de ingreso medio representan el 75\% de la población mundial y aproximadamente el $30 \%$ de la demanda agregada del mundo, y lo que es más importante, estos países representan el $96 \%$ de la deuda pública de los países en desarrollo (con exclusión de China y la India) (véase el cuadro 2)

Cuadro 2 | Grupos de países según su ingreso: deuda externa pública y con garantía pública

(En millones de dólares y en porcentajes del total)

\begin{tabular}{lcc}
\hline Grupo & Millones de dólares & Porcentajes \\
\hline Países de ingreso bajo y medio & 2923874 & 100 \\
\hline Países de ingreso bajo & 118111 & 4,0 \\
\hline Países de ingreso medio-bajo (con exclusión de la India) & 1021506 & 34,9 \\
\hline Países de ingreso medio-alto (con exclusión de China) & 1784258 & 61,0 \\
\hline Países de ingreso medio (con exclusión de China y la India) & 2805763 & 96,0 \\
\hline
\end{tabular}

Fuente: Banco Mundial, International Debt Statistics 2021, 2020 [en línea] https://data.worldbank.org/products/ids.

\footnotetext{
32 Los fondos propios están constituidos por el capital desembolsado y las reservas acumuladas. Los préstamos abarcan los préstamos, las garantías y las inversiones de capital realizadas con fines de desarrollo.
} 


\section{Se debe profundizar en las iniciativas vigentes destinadas a reducir la deuda, como la Iniciativa de Suspensión del Servicio de la Deuda, aumentando la escala, el alcance y el plazo de estas, e incluyendo a todas las partes interesadas}

- La Iniciativa de Suspensión del Servicio de la Deuda lanzada por el G20 en abril de 2020 consiste en una suspensión temporal del reembolso de los préstamos de acreedores bilaterales oficiales. La suspensión se extiende desde marzo de 2020 hasta junio de 2021 y solo se aplica a los 76 países que cumplen con los requisitos para recibir ayuda de la Asociación Internacional de Fomento (AIF) del Banco Mundial, y a todos los países que las Naciones Unidas han definido como países menos desarrollados. Hasta noviembre de 2020, solo 46 países habían solicitado un alivio de la deuda en el marco de esta iniciativa: 28 del África Subsahariana, 8 de Asia y el Pacífico, 7 de Oriente Medio, y 3 de América Latina y el Caribe (Dominica, Granada y Santa Lucía).

- Además de que se centra principalmente en los países de ingreso bajo y deja fuera a la mayoría de los de ingreso medio, la Iniciativa de Suspensión del Servicio de la Deuda no incluye a todas las partes interesadas. De hecho, el sector privado y las instituciones multilaterales no participan en la iniciativa.

- En 2020, los acreedores bilaterales oficiales representaban aproximadamente el $44,4 \%$ de todo el servicio de la deuda, lo que supone un gran avance. De todos modos, la mayor parte de dicho servicio - un 25,5\% y un 30,1\%, respectivamente-corresponde a los acreedores privados y a los multilaterales, que no participan en la Iniciativa de Suspensión del Servicio de la Deuda. En los casos de Dominica, Granada y Santa Lucía, los acreedores multilaterales y privados también representan la mayor parte del servicio de la deuda (véase el cuadro 3), y el ahorro que se obtuvo al participar en la mencionada iniciativa es pequeño desde cualquier punto de vista (un 0,70\%, un $0,72 \%$ y un $0,27 \%$ del PIB en 2020 , respectivamente).

Cuadro 3 | Dominica, Granada, Santa Lucía y todos los países del mundo que participan en la Iniciativa de Suspensión del Servicio de la Deuda: servicio de la deuda por tipo de acreedor, 2020

(En porcentajes del total)

\begin{tabular}{lcccc}
\hline Tipo de acreedor & Todos los países participantes & Dominica & Granada & Santa Lucía \\
\hline Privados & 25,5 & 18,0 & 25,0 & 1,0 \\
\hline Oficiales multilaterales & 30,1 & 49,0 & 58,0 & 74,0 \\
\hline Oficiales bilaterales & 44,4 & 25,0 & 17,0 & 25,0 \\
\hline No oficiales & $\ldots$ & 8,0 & 0,0 & - \\
\hline
\end{tabular}

Fuente: Banco Mundial, “COVID-19: Debt Service Suspension Initiative", 2020 [en línea] https://www.worldbank.org/en/topic/debt/brief/covid-19-debtservice-suspension-initiative y Red Europea sobre Deuda y Desarrollo (EURODAD), La Iniciativa de Suspensión del Servicio de la Deuda del G20: ¿drenar el Titanic con un balde?, octubre de 2020.

- En noviembre de 2020, el G20 propuso un marco común para tratar la deuda más allá de la Iniciativa de Suspensión del Servicio de la Deuda. Dicho marco tiene por objeto llenar algunas de las lagunas que tiene esta última; por ejemplo, incluir a los acreedores oficiales que no forman parte del Club de París (es decir, China). También supone que los acreedores bilaterales oficiales negocien de forma conjunta con un país deudor dado, y contempla la posibilidad de que el país deudor solicite que el sector privado le dé un tratamiento equivalente al que ofrecen dichos acreedores (G-20, 2020).

\section{Las iniciativas de alivio de la deuda requieren cambios en la arquitectura de la deuda internacional}

- Es necesario que haya un mecanismo internacional de reestructuración de la deuda soberana para hacer frente a las obligaciones contraídas con los acreedores privados. Un ejemplo de esta necesidad son las reestructuraciones que en 2020 se pusieron en práctica con acreedores privados en la Argentina, el Ecuador y Suriname, que, en ausencia de dicho mecanismo, llevaron a que se adoptaran duras medidas de austeridad.

- Un mecanismo de reestructuración de la deuda soberana va de la mano de la creación de una agencia multilateral de calificación crediticia que pueda servir de contrapeso al actual monopolio que hay en ese ámbito ${ }^{33}$. Una agencia como esa podría evitar los conflictos de intereses entre el sector privado y el público.

33 Las "tres grandes" agencias de calificación crediticia -Moody's, Standard \& Poor's (S\&P) y Fitch Ratings- controlan alrededor del 95\% de las calificaciones crediticias de los mercados financieros. 
- El hecho de que las agencias privadas de calificación crediticia evalúen el riesgo implica que la autoridad reguladora del gobierno (al que normalmente se le encomienda esta tarea) se transfiere al sector privado. Esto puede crear problemas importantes, ya que el mandato de las agencias de calificación crediticia no es proporcionar información ni evaluar el riesgo crediticio en interés de los objetivos públicos, sino maximizar los beneficios y el valor para los accionistas (Gavras, 2012).

- Las agencias de calificación crediticia son algo más que simples formadoras de opinión: tienen una influencia considerable en las fluctuaciones del mercado. En consecuencia, pueden incidir no solo en el valor de los activos y las garantías (los colaterales), sino también en la volatilidad y la estabilidad financiera. Esto es especialmente cierto en el caso de la crisis del COVID-19, ya que los mercados de capitales privados (los mercados de bonos) se han convertido en una importante fuente de financiamiento para los países en desarrollo, entre ellos los de América Latina y el Caribe ${ }^{34}$. Entre enero y octubre de 2020, en 17 países de la región se emitieron bonos por un valor total de 122.000 millones de dólares, lo que supera el importe emitido en todo 2019 (118.000 millones de dólares) ${ }^{35}$.

- Modificar el modo en que se evalúa el riesgo podría evitar la ola de rebajas de las calificaciones crediticias y de las perspectivas económicas que se han producido desde el inicio de la pandemia y que han afectado a las economías de América Latina y el Caribe.

- Durante 2020 se rebajó la calificación crediticia de 13 países latinoamericanos: Argentina, Bahamas, Belice, Bolivia (Estado Plurinacional de), Colombia, Costa Rica, Ecuador, Guatemala, Jamaica, México, Nicaragua, Suriname, y Trinidad y Tabago. El mayor número de rebajas se registraron en el Ecuador, seguido de Suriname y la Argentina (8, 7 y 4, respectivamente) (CEPAL, 2020c).

- Durante una crisis sistémica como la del COVID-19 y unas condiciones mundiales muy inciertas, es necesario volver a evaluar la eficacia y la objetividad de las calificaciones, así como las del momento en que se anuncian. El gasto en respuesta a la pandemia y el aumento del endeudamiento podrían desencadenar revisiones y rebajas de la calificación crediticia, lo que podría provocar salidas de capital, aumentar el costo de este y del acceso al crédito, y empeorar la situación financiera. Las rebajas crediticias suelen agravar las condiciones financieras en un momento en que el financiamiento es muy necesario para combatir los efectos corrosivos de las crisis.

- Las iniciativas de reducción de la deuda no garantizan una mayor liquidez. Por ello, la reducción debe complementarse con inyecciones de liquidez, controles permanentes del capital (o regulaciones de la cuenta de capital) y una política fiscal proactiva. La regulación macroprudencial y de la cuenta de capital es necesaria no solo para evitar la inestabilidad financiera, sino también para aplicar con eficacia políticas fiscales y monetarias expansivas que promuevan la recuperación.

\section{Hay que delinear una estrategia de reducción de la deuda que no adopte un enfoque único y que tenga en cuenta la heterogeneidad de los perfiles de endeudamiento y la vulnerabilidad de la deuda en la región}

- Para tratar el problema de la deuda en América Latina y el Caribe, es necesario diseñar una estrategia de acuerdo con tres ejes de acción.

- En primer lugar, todas las economías muy endeudadas deberían poder acogerse al alivio oficial de la deuda, a las moratorias o a ambos beneficios. El elevado endeudamiento público externo se puede ejemplificar con el caso de la Argentina, cuya deuda representaba un $68 \%$ del PIB en el tercer trimestre de 2020, y el de la mayoría de los PEID del Caribe, en particular Barbados, Belice, Suriname y las Bahamas, cuya deuda representaba un $117,4 \%$, un $114,2 \%$, un $95,3 \%$ y un $74 \%$ del PIB, respectivamente, en septiembre de 2020.

- En segundo lugar, las economías en que el perfil de endeudamiento es de corto plazo o en que la carga del servicio de la deuda es elevada también deberían tener derecho a algún tipo de alivio de la deuda. Los PEID del Caribe y los países de Centroamérica enfrentan obligaciones considerables a corto plazo vinculadas con el servicio de la deuda. Los pagos de dicho servicio ascienden en promedio al 30\% de los ingresos públicos de los países del Caribe y al 2,8\% del PIB de los de Centroamérica.

- Los argumentos a favor de aliviar la deuda del Caribe se ven reforzados por el hecho de que la acumulación de deuda está impulsada por perturbaciones exógenas (riesgos naturales) y por las características estructurales asociadas a que son países de tamaño pequeño. Las repercusiones de la pandemia de COVID-19 no solo aumentarán la carga de la deuda, sino que también conducirán a una reasignación del presupuesto existente.

\footnotetext{
34 Sin embargo, como se desprende de los datos más recientes, los mercados privados internacionales pueden ser muy volátiles y, por tanto, podrian no constituir una fuente fiable de financiamiento a largo plazo.

35 Históricamente, las tasas bajas de interés de las economías desarrolladas (que son resultado de las políticas monetarias expansivas) han animado a los inversores a comprar deuda de mercados en desarrollo para obtener mayores beneficios. Los datos disponibles con respecto al período $2017-2019$ muestran que la rentabilidad aumentó en el transcurso de 2020 (es decir, durante la pandemia). La rentabilidad se determina de forma indirecta calculando la diferencia entre la tasa de interés que se aplica a las emisiones de deuda en el mercado internacional de capitales y la tasa de interés libre de riesgo de los bonos a diez años del Departamento del Tesoro de los Estados Unidos.
} 
- Por último, los países que, según los estándares internacionales, tienen un mayor margen fiscal y una situación fiscal o macroeconómica más sólida (como Chile, Colombia y el Perú) pueden aprovechar los niveles históricamente bajos de las tasas de interés internacionales a largo plazo y el impulso que estas han dado al mercado internacional de bonos.

- La política fiscal también puede desempeñar un papel importante a la hora de promover la sostenibilidad de la deuda pública. A corto plazo, en los países se están financiando las medidas de emergencia mediante una combinación de ajustes presupuestarios, aumentos del gasto público, medidas de reducción de impuestos y medidas de liquidez, entre ellas las garantías públicas de crédito. A más largo plazo, la reducción de los flujos ilícitos, como la evasión y la elusión de impuestos (que en 2018 representaron un 6,1\% del PIB o 325.000 millones de dólares), junto con reformas fiscales progresivas que aumenten la recaudación de los impuestos sobre la renta de las personas físicas y sobre el patrimonio, podrían proporcionar ingresos adicionales y reducir la desigualdad de los ingresos. Además, la recaudación fiscal se podría diversificar y reforzar gravando la economía digital y estableciendo impuestos medioambientales e impuestos correctivos destinados a abordar problemas de salud pública, como el alcohol, el tabaco, y las bebidas y alimentos con alto contenido de azúcar y calorías.

\section{F. Cuarta medida de política: proporcionar a los países un conjunto de instrumentos innovadores destinados a aumentar la capacidad de reembolso de la deuda y evitar el endeudamiento excesivo}

\section{Las cláusulas sobre los huracanes deberían aparecer siempre en las iniciativas encaminadas a aliviar la deuda de países como los del Caribe, que están constantemente expuestos a peligros naturales}

- En el caso de economías como las del Caribe, la exposición constante a peligros naturales y a sus devastadores efectos sociales y económicos puede empeorar la situación financiera y llevar al endeudamiento excesivo. Las cláusulas sobre los huracanes permiten aplazar el pago del servicio de la deuda, tanto en lo que atañe al capital como a los intereses, o brindan la posibilidad de acelerar las operaciones de reestructuración de esta, en caso de que ocurra un huracán (u otro desastre natural asegurado).

- El caso de Granada, en que se incluyeron cláusulas sobre los huracanes como parte de una reestructuración integral de la deuda pública que redujo el endeudamiento del país, ofrece importantes lecciones sobre cómo aplicar bien estas cláusulas (véase el gráfico 9) ${ }^{36}$.

Gráfico 9 | Granada: evolución de la relación entre la deuda y el PIB, 2010-2019 (En porcentajes)

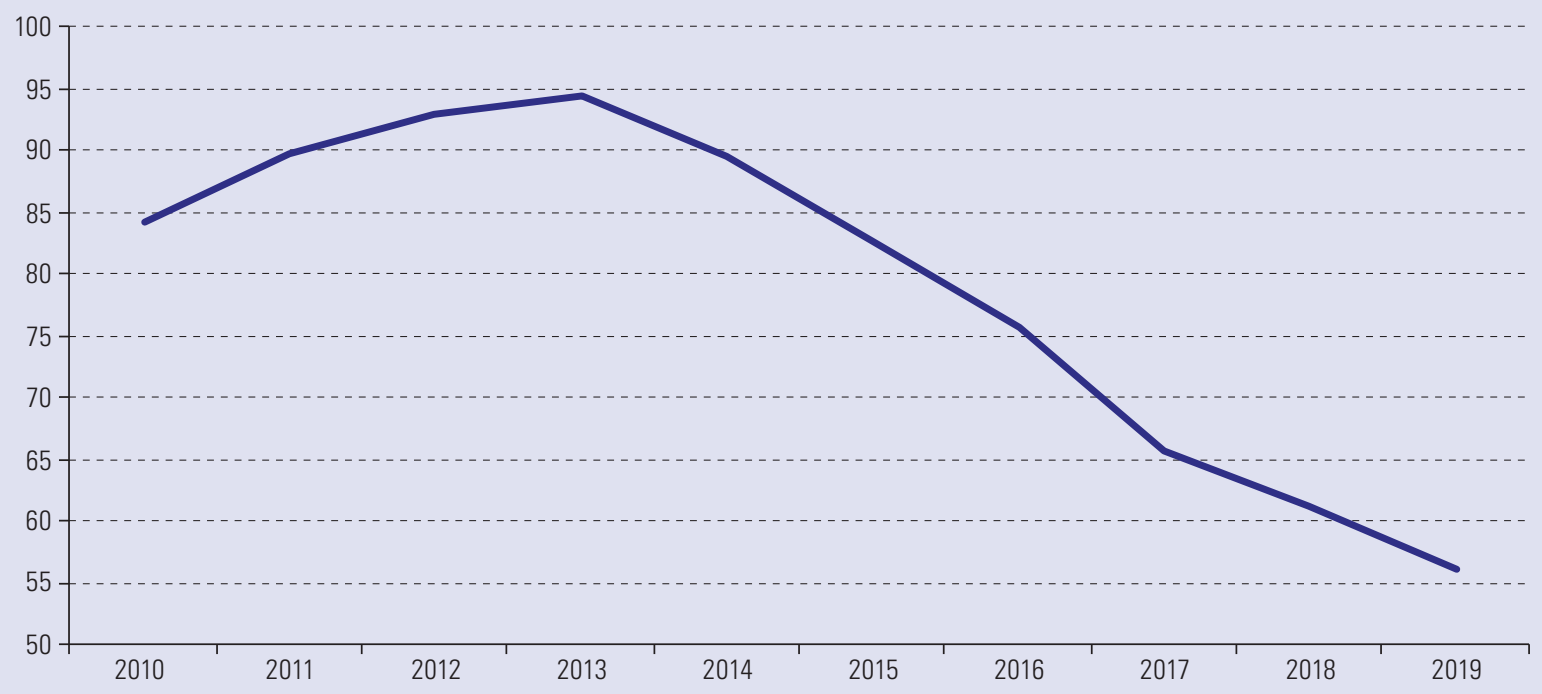

Fuente: Comisión Económica para América Latina y el Caribe (CEPAL), sobre la base de información oficial, 2020.

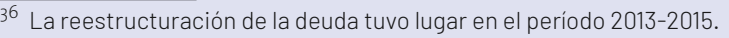


- Los datos y la experiencia adquirida indican que las cláusulas sobre los huracanes deben abarcar una cantidad importante de la deuda del país y tener una duración adecuada para ofrecer el margen fiscal necesario en caso de que ocurra un desastre natural.

- Asimismo, para garantizar el éxito de la iniciativa es necesario contar con el apoyo y el respaldo de los acreedores multilaterales, ya que estos pueden aportar la confianza y la credibilidad que se necesitan para que el sector privado participe. Por último, la experiencia en relación con las cláusulas sobre los huracanes indica que estas conllevan concesiones (trade-offs) económicas y financieras que deben evaluarse (Commonwealth Secretariat, 2016).

- Cuando se aplaza el pago del servicio de la deuda, la moratoria da lugar a desembolsos más grandes en el futuro debido a la capitalización del pago de los intereses. Los países deben tener la capacidad de reembolso necesaria para solventar esos desembolsos; de lo contrario, la moratoria no hace más que aplazar el endeudamiento excesivo y la falta de pago.

\section{A un nivel más general, la experiencia con los bonos asociados a los huracanes subraya la necesidad de vincular la capacidad de reembolso al desempeño de la economía o al ciclo económico, como ocurre con otros instrumentos innovadores que merecen ser explorados, como los instrumentos vinculados al ingreso nacional y los de deuda estatales contingentes para soberanos}

- Los bonos vinculados al ingreso nacional son un instrumento anticíclico en que el reembolso de la deuda se vincula con la capacidad de reembolsar que hay en el país. Estos bonos son una manera de extender los bonos vinculados al PIB a las economías en desarrollo, y en ellos se tiene en cuenta la importancia del sector externo, a saber, las exportaciones, las importaciones y los términos de intercambio, a la hora de determinar las fluctuaciones económicas de un país. Los bonos vinculados al ingreso nacional pueden ofrecer menos riesgo y, por tanto, más credibilidad para los inversores, que los bonos vinculados al PIB, ya que incluyen más elementos exógenos que dificultan la manipulación de las cifras ${ }^{37}$.

- Este instrumento reduce la carga de la deuda cuando la economía se encuentra en un período de crecimiento lento, situación que normalmente va acompañada de una reducción de los ingresos públicos. En este sentido, los bonos vinculados al ingreso nacional proporcionan un mecanismo de seguro contra las crisis de liquidez fiscal en los malos tiempos, y con ello reducen la probabilidad de que se suspenda el pago de la deuda y de que haya que reestructurarla ${ }^{38}$.

- Los instrumentos de deuda estatales contingentes para soberanos son otro instrumento de deuda dependiente que permite paralizar el pago (ya sea de los intereses o del capital) o prorrogar el vencimiento cuando uno o varios indicadores particulares superan un umbral determinado. Su objetivo es permitir que el gobierno haga frente a la falta de liquidez y a las crisis de liquidez. Además, estos instrumentos podrían contribuir a evitar las crisis de solvencia. Como en el caso de los bonos vinculados al ingreso nacional, estos instrumentos proporcionan un respiro a corto plazo, ya que permiten afrontar las crisis de liquidez. Como en el caso de los bonos vinculados al $\mathrm{PIB}$, también permiten repartir mejor el peso de la carga entre los acreedores del sector privado. Además, reducen la cuantía de las ayudas del sector oficial.

\footnotetext{
37 Como en los demás instrumentos financieros, en los bonos vinculados al PIB hay dos partes: el emisor, que en este caso es el gobierno, y el inversor. Los pros y los contras de estos bonos deben considerarse desde ambas perspectivas. Los principales beneficios para el emisor son los siguientes: la reducción del riesgo de impago y de los diferenciales de crédito; la reducción de los costos del servicio; el aumento del margen fiscal; la mitigación de la prociclicidad, y el hecho de que el riesgo se comparte. El principal beneficio para el inversor es que un bono vinculado al PIB proporciona una fuente de ingresos más amplia, más estable y menos volátil. Las principales reservas conciernen al inversor. Una de ellas se refiere a que los funcionarios públicos podrían sentirse tentados de manipular los datos con el fin de mostrar un menor crecimiento del PIB, lo que podría llevar a que los inversores aumentaran la prima (como reflejo de la pérdida de confianza en los datos del gobierno). Otras reservas que atañen al uso de este instrumento y que pueden socavar su viabilidad son la falta de liquidez, la ausencia de mercados que cubran el riesgo asociado al PIB y las dificultades para fijar los precios.

38 Entre los países que han emitido bonos con aspectos indizados al PIB se encuentran Bulgaria(1994), Bosnia y Herzegovina(1997), la Argentina(2005), Singapur (2011) y Grecia (2012). El último experimento es el de Italia (Spence y Speciale, 2020). La mayoria de los datos empíricos disponibles sobre el rendimiento de este instrumento se refieren a paises desarrollados. Los datos señalan que los beneficios de los bonos vinculados al PIB en lo que concierne a la reducción del riesgo de impago son mayores para los países que tienen las siguientes características: i) una menor calificación crediticia; ii) un PIB más volátil, y iii) una política monetaria más restringida (véanse Benford y otros, 2016, y Barr, Bush y Pienkowski, 2014).
} 


\section{G. Quinta medida de política: integrar las medidas de liquidez y de reducción de la deuda a una estrategia de financiamiento para el desarrollo encaminada a construir un futuro mejor}

\section{Afrontar la emergencia de la pandemia requiere un gasto público importante}

- El aumento del financiamiento, el mejor acceso a este y el apoyo a las iniciativas de reducción de la deuda son fundamentales para sostener los esfuerzos relacionados con la demanda y la oferta encaminados a hacer frente a la urgencia de la pandemia, que aún está vigente. Esto supone aumentar el gasto sanitario para contener la propagación de la epidemia. Además, es necesario aumentar el gasto público para compensar los efectos perjudiciales que las políticas de contención (el distanciamiento físico y las cuarentenas) tienen sobre la actividad económica, el tejido productivo (la estructura productiva) y el empleo. Asimismo, dado que el tiempo es esencial a la hora de intervenir en esta crisis, los gobiernos deben proporcionar un apoyo rápido y urgente a las empresas y a los trabajadores, además de propiciar el funcionamiento adecuado de las relaciones laborales y los mercados de trabajo. La falta de apoyo adecuado podría dar como resultado la destrucción permanente de la capacidad productiva y el deterioro de las condiciones sociales y la institucionalidad laboral debido al aumento del desempleo y la informalidad. Esto también podría dar lugar a la posibilidad de que surgieran conflictos sociales en el futuro.

\section{En las políticas destinadas a hacer frente a los efectos económicos y sociales del COVID-19 se debe vincular la fase de corto plazo (de emergencia) con la de largo plazo}

- La forma en que se encare el corto plazo determinará en gran medida cómo será el mediano y el largo plazo. Ambas perspectivas deben integrarse para reconfigurar el modelo de desarrollo hacia la transformación productiva con sostenibilidad e igualdad. Para ello, la labor de recuperación debe centrarse en fomentar la resiliencia.

- Como ya se ha mencionado, los bancos de desarrollo multilaterales, regionales, subregionales y nacionales pueden desempeñar un papel clave y encabezar la labor de recuperación aumentando la capitalización y flexibilizando los criterios de concesión de préstamos. Además, el Banco Mundial debería equilibrar mejor la asignación de crédito entre el crédito que otorga a los países de ingreso medio, incluidos los de América Latina y el Caribe, y el que concede a los de ingreso bajo.

- El Banco Mundial ha respondido a la pandemia con un paquete importante de 160.000 millones de dólares centrado en la salud, en proteger a los pobres y los vulnerables, en garantizar un crecimiento sostenible de las empresas y el empleo, en fortalecer las políticas y las instituciones, y en fomentar la inversión a fin de reconstruir mejor. Sin embargo, está previsto que América Latina y el Caribe reciba solo un 2,8\% del total (4.500 millones de dólares).

- Los datos disponibles indican que el Banco Mundial ha centrado su labor sobre todo en los países de ingreso bajo. El aumento de los préstamos concedidos a esos países a través de la Asociación Internacional de Fomento (AIF) para hacer frente a los efectos de la pandemia superó el que tuvo lugar durante la crisis financiera mundial: los préstamos aumentaron un $26 \%$ entre 2008 y 2009, y un $49 \%$ entre 2019 y 2020 . Por el contrario, el crédito otorgado a los países de ingreso medio a través del Banco Internacional de Reconstrucción y Fomento (BIRF) aumentó mucho más durante la crisis financiera mundial que en el contexto actual (véase el gráfico 10).

- Asimismo, los bancos de desarrollo pueden contribuir a la recuperación dejando de priorizar los préstamos destinados a dar respuesta inmediata a la emergencia, a medida que esta se vaya controlando, para priorizar los que tienen por objeto alcanzar objetivos de desarrollo a mediano y largo plazo. El aumento del financiamiento debe ir acompañado de cambios en la composición de la cartera de préstamos.

- En el mandato de los bancos de desarrollo se debería contemplar que un porcentaje considerable de la cartera de préstamos se canalizara hacia las inversiones verdes y los proyectos relacionados con el cambio climático. Para que en el sistema de la banca de desarrollo se articule una estrategia coherente encaminada hacia el financiamiento verde es necesario que los bancos multilaterales de desarrollo apoyen a los bancos subregionales y nacionales para que accedan a financiamiento de bajo costo, a capital de largo plazo y a la capacidad técnica que les permita acceder a los fondos y diseñar proyectos. 
Gráfico 10 | Banco Mundial (incluidos el Banco Internacional de Reconstrucción y Fomento y la Asociación Internacional de Fomento) y Banco Interamericano de Desarrollo: aumento del crédito otorgado durante la crisis financiera mundial (2008-2009) y la pandemia de COVID-19

(En porcentajes)

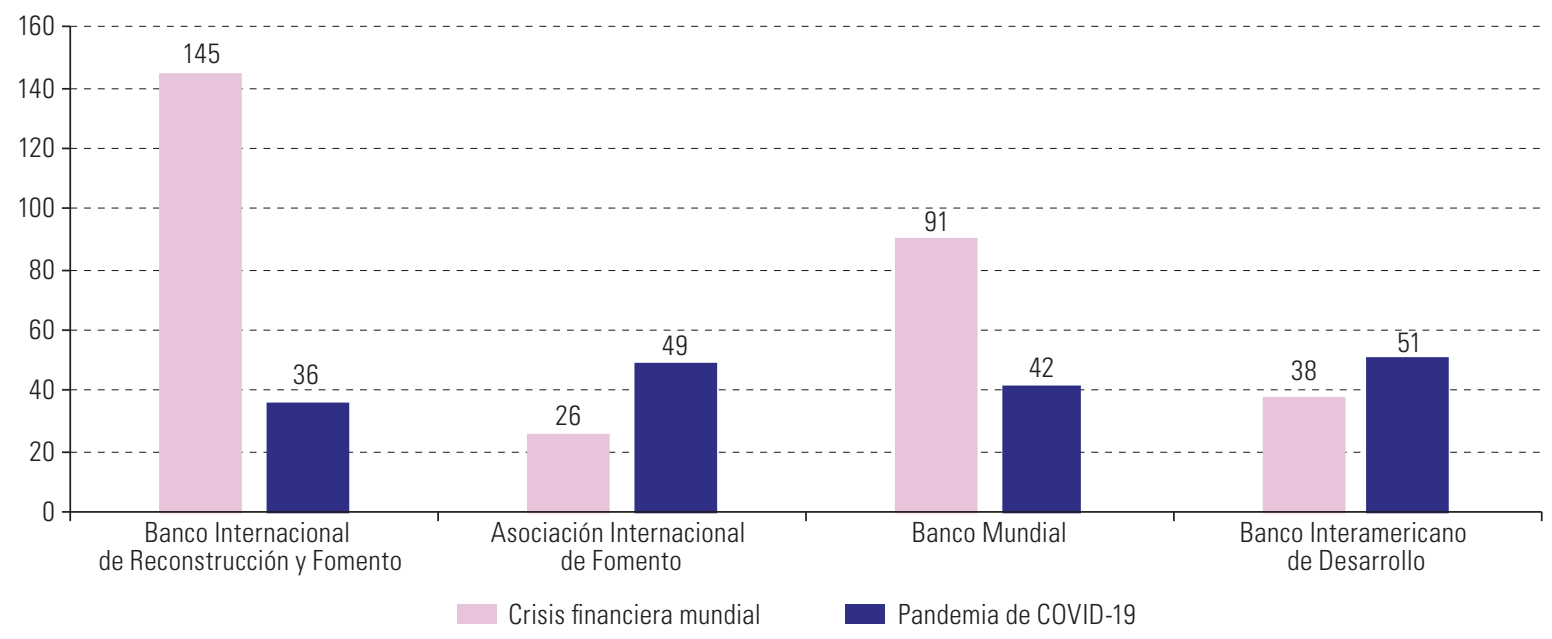

Fuente: C. Humphrey y A. Prizzon, "Scaling up multilateral bank finance for the Covid-19 recovery", ODI Insight, 18 de noviembre de 2020 [en línea] https://www.odi.org/blogs/17570-scaling-multilateral-bank-finance-covid-19-recovery\#review-of-mdbs.

- La comunidad internacional puede apoyar la tarea de reconstruir mejor de las siguientes maneras: eliminando las barreras de acceso a la tecnología ambiental; fomentando las innovaciones mediante la expansión de las prácticas de habilitación obligatoria en los países en desarrollo; promoviendo la aplicación de la ley de competencia, y proponiendo una nueva declaración mundial de desarrollo (en el sentido de la Declaración de Doha) relativa a los derechos de propiedad intelectual y el cambio climático. Asimismo, es importante crear un fondo común voluntario de patentes ambientales y hacer cumplir los compromisos de financiamiento para el clima a fin de ayudar a los países en desarrollo, como se prevé en el Acuerdo de París. En esa misma línea, la creación de empleo y los programas de empleo pueden vincularse con el desarrollo de la economía verde.

- La mayor atención a la economía verde puede vincularse con programas de empleo de emergencia que promuevan la restauración de los ecosistemas y estimulen el uso de soluciones basadas en la naturaleza (SBN). Esto puede lograrse por los siguientes medios: la protección, la restauración o la gestión de los bosques naturales y los humedales en las cuencas hidrográficas, para preservar una barrera que proteja las comunidades costeras contra las inundaciones; la creación de un programa de gran envergadura destinado a pagar a los desempleados o a las comunidades vulnerables por restaurar los paisajes, y la revegetación urbana, la agricultura urbana y el turismo de naturaleza. En la misma línea, los flujos de la asistencia oficial para el desarrollo (AOD) —que debería proporcionarse sobre la base de criterios distintos del PIB per cápita- deberían destinarse en su mayor parte (al menos un $50 \%$ del total) a la transformación de la matriz productiva (energías renovables) y a la acumulación de capital humano (educación) ${ }^{39}$.

- La construcción de un modelo de desarrollo más sostenible desde el punto de vista ambiental que ofrezca mayores beneficios sociales puede verse facilitada por el creciente interés de los mercados financieros privados en los bonos sociales y sostenibles que se emiten en las economías de los mercados emergentes ${ }^{40}$. Los datos disponibles correspondientes al período 2016-2020 muestran que las emisiones de bonos sociales aumentaron de 0 a 17.000 millones de dólares, y las de bonos sostenibles, de 300 a 10.900 millones de dólares (véase el gráfico 11). En América Latina y el Caribe, Chile y México son dos de los países que han aprovechado el entusiasmo inversor para emitir bonos vinculados a la sostenibilidad ${ }^{41}$.

39 Los datos disponibles en relación con los países de América Latina y el Caribe que se han graduado de la AOD -entre ellos, Barbados, Chile, Trinidad y Tabago y el Uruguay - indican que, en los años previos al proceso de graduación, el grueso de los flujos de AOD se canalizó hacia la educación y la energía renovable (CEPAL, 2020d)

40 Los bonos sociales son emisiones de bonos destinados a proyectos que se diseñan para tener un impacto social positivo. El desarrollo comunitario, así como la vivienda y la infraestructura asequibles, son algunos ejemplos de este tipo de proyectos. Los bonos sostenibles son emisiones de bonos que tienen por objeto financiar proyectos nuevos y existentes diseñados para tener una repercusión positiva sobre el medio ambiente. Algunos ejemplos de este tipo de proyectos son los que se relacionan con las energías renovables, el transporte limpio, la eficiencia energética, la gestión del agua y los residuos, y los edificios ecológicos. También incluyen el financiamiento de proyectos relacionados con la salud (Mutua, 2021).

${ }^{41}$ En 2020, el Gobierno federal de México emitió un bono soberano vinculado con los Objetivos de Desarrollo Sostenible; el bono es a siete años y representa 890 millones de dólares. En el bono se da prioridad a las poblaciones vulnerables y se adopta un criterio de gobernanza vinculado con la participación de una organización de las Naciones Unidas. Por otra parte, en Chile se emitió el mayor bono sostenible que un gobierno latinoamericano haya emitido en los mercados de deuda extranjera. La emisión consistía en bonos sostenibles por 1.500 millones de dólares y 1.650 millones de euros (2.000 millones de dólares) en los mercados europeos para financiar proyectos verdes y sociales. 
Gráfico 11 | Emisiones de bonos sociales y sostenibles en las economías de mercado emergentes, 2016-2020 (En millones de dólares)

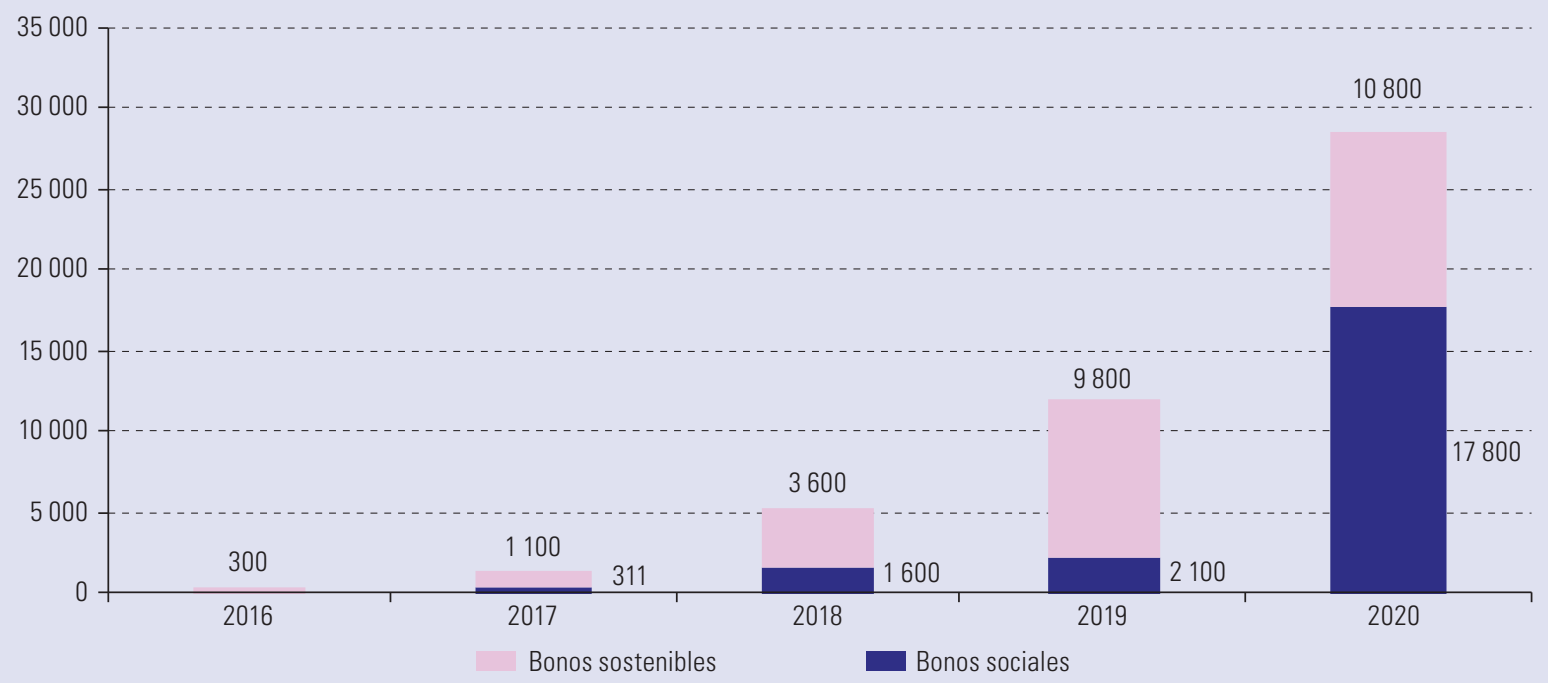

Fuente: D.C. Mutua, “Chile Sells Biggest Latin American Sovereign Sustainability Bond", Bloomberg, 20 de enero de 2021 [en línea] https://www.bloomberg. com/news/articles/2021-01-20/chile-sells-biggest-latin-american-sovereign-sustainability-bond.

\section{A nivel subregional se puede promover la resiliencia mediante iniciativas como el Fondo de Resiliencia del Caribe}

- El Fondo de Resiliencia del Caribe se dedicará a atraer financiamiento a gran escala y de bajo costo para destinarlo a invertir en sectores verdes, a reducir la deuda mediante el canje de esta por adaptación al clima, y a apoyar la inversión en proyectos que fomenten la resiliencia.

- Los recursos de este fondo se utilizarían para financiar iniciativas relacionadas con políticas industriales verdes, infraestructura y creación de resiliencia en general; en los PEID del Caribe, como en otras partes de América Latina y el Caribe, esto debería ser un componente crucial de la labor de recuperación, y una oportunidad para diversificarse y crear empleo. Además de atraer financiamiento en condiciones favorables y otras fuentes de financiamiento, el Fondo de Resiliencia del Caribe se financiaría mediante una reducción de la deuda que representaría el 12,2\% del total de la deuda pública de los PEID del Caribe, lo que ascendería a solo 7.000 millones de dólares.

\section{H. La crisis actual debe aprovecharse como una oportunidad para alcanzar un amplio consenso social y político que permita aplicar reformas ambiciosas con el fin de emprender un proceso de construcción sostenible e igualitario hacia el futuro}

- Construir un futuro mejor significa poner la igualdad y la sostenibilidad ambiental en el centro de la fase de recuperación. Esto supone prestar servicios públicos universales de alta calidad —entre ellos, educación, salud, transporte y servicios ambientales-y ampliar el acceso a ellos, para así aumentar el sentido de pertenencia de la población y reducir los déficits de bienestar, que desde antes de la pandemia ya provocaban malestar social y político en muchos países.

- Afrontar y superar los efectos de la pandemia en sus diferentes dimensiones no depende del financiamiento necesario, que es modesto desde cualquier punto de vista, sobre todo en comparación con la magnitud de los paquetes de estímulo que se introdujeron en las economías desarrolladas, donde el costo del endeudamiento es más bajo y hay un mayor margen fiscal ${ }^{42}$. Lograr ese objetivo depende en parte de que se reconozca que la acción colectiva y la solidaridad son la única manera de responder a la urgencia y a los retos de mediano y largo plazo que plantea una crisis sistémica como la del COVID-19.

\footnotetext{
$\overline{42}$ Los paquetes de estímulo fiscal y monetario, que se implementaron en su gran mayoría en los paises desarrollados, se estiman en 12 y 7,5 billones de dólares, respectivamente.
} 
- Para llevar a cabo una acción colectiva es necesario que haya cooperación multilateral exterior, lo que supone ampliar y redistribuir la liquidez, y que se reforme la arquitectura de la deuda multilateral de modo que en los países se pueda hacer frente a las obligaciones financieras y aplicar políticas fiscales expansivas sin obstaculizar el desarrollo futuro.

- La orientación de las políticas de los países de América Latina y el Caribe también es fundamental a los efectos de construir un futuro mejor. El margen para aplicar políticas se puede aumentar si se eliminan la elusión y la evasión fiscales, y se hace caer el peso de la tributación en los impuestos directos y los que gravan la propiedad y el patrimonio. También se puede reorientar el gasto público hacia la creación de empleo y las actividades que son transformadoras y ambientalmente sostenibles. Para ello, en dicho gasto se deben priorizar la inversión pública, el ingreso básico, la protección social universal, el apoyo a las pequeñas y medianas empresas (pymes), la inclusión digital y el desarrollo de tecnologías verdes.

\section{Bibliografía}

Alonso, J. A. y J. A. Ocampo (2020), Trapped in the Middle?: Developmental Challenges for Middle-Income Countries, Oxford, Oxford University Press.

Banco Mundial (2020a), International Debt Statistics 2021 [en línea] https://data.worldbank.org/products/ids. (2020b), "COVID-19: Debt Service Suspension Initiative" [en línea] https://www.worldbank.org/en/topic/ debt/brief/covid-19-debt-service-suspension-initiative.

_ (2020c), Informe Anual 2020: apoyo a los países en una época sin precedents [en línea] https://www. worldbank.org/en/about/annual-report.

Barr, D., O. Bush y A. Pienkowski (2014), "GDP-linked bonds and sovereign default", Life After Debt the Origins and Resolutions of Debt Crisis, J. Stiglitz y D. Heymann (eds.), Londres, Palgrave Macmillan.

Benford, J. y otros (2016), "Sovereign GDP-linked bonds", Financial Stability Paper, No 39, Bank of England, 26 de septiembre.

Bisogno, M. y P. Fleiss (2020), "Multilateral development banks in Latin America and the Caribbean: recent trends, the response to the pandemic, and the forthcoming role", documento encargado por la oficina de la CEPAL en Washington, D.C, borrador, diciembre, inédito.

CEPAL (Comisión Económica para América Latina y el Caribe) (2020a), Balance Preliminar de las Economías de América Latina y el Caribe, 2020 (LC/PUB.2020/17-P), Santiago.

_-(2020b), La Inversión Extranjera Directa en América Latina y el Caribe, 2020 (LC/PUB.2020/15-P), Santiago.

(2020c), Capital Flows to Latin America and the Caribbean (LCMAS/TS.2019/6), Washington, D.C., diciembre.

_ (2020d), "El proceso de graduación y los costos potenciales de la graduación," inédito.

_ (2017), Estudio Económico de América Latina y el Caribe, 2017 (LC/PUB.2017/17-P), Santiago.

_.2012), Los países de renta media: un nuevo enfoque basado en brechas estructurales (LC/G.2532/Rev.1), Santiago.

CEPAL (Comisión Económica para América Latina y el Caribe)/Misión Permanente de Costa Rica ante las Naciones Unidas (2020), "International Solidarity in the Face of the Economic Recession caused by COVID-19: Presentation of the Fund Against COVID-19 Economics (FACE). Convened by the President of Costa Rica", 25 de septiembre.

Commonwealth Secretariat (2016), Introducing Hurricane Clauses Lessons from Grenada's recent experience: A countercyclical financial instrument, Londres.

EURODAD (Red Europea sobre Deuda y Desarrollo) (2020), La Iniciativa de Suspensión del Servicio de la Deuda del G20: ¿drenar el Titanic con un balde?, octubre.

FLAR (Fondo Latinoamericano de Reserva) (2020), "FLAR strengthens itself to support its member countries in the COVID-19 crisis" [en línea] https://www.flar.net/en/news/flar-strengthens-itself-support-its-membercountries-covid-19-crisis.

FMI (Fondo Monetario Internacional) (2021a), "Weekly Report on Key Financial Statistics. As of January 29, 2021 ". (2021b), World Economic Outlook Database [en línea] http://www.imf.org/external/ns/cs.aspx?id=28.

_ (2021c), World Economic Outlook Update, enero [en línea] https://www.imf.org/en/Publications/WEO/ Issues/2021/01/26/2021-world-economic-outlook-update.

_ (2020a), "SDRs per Currency unit and Currency units per SDR last five days" [en línea] https://www.imf. org/external/np/fin/data/rms_five.aspx.

(2020b), "Transcript of Press Briefing by Kristalina Georgieva following a Conference Call of the International Monetary and Financial Committee" [en línea] https://www.imf.org/en/News/Articles/2020/03/27/tr032720transcript-press-briefing-kristalina-georgieva-following-imfc-conference-call. 
(2020c), "IMF Flexible Credit Line (FCL)" [en línea] https://www.imf.org/en/About/Factsheets/ Sheets/2016/08/01/20/40/Flexible-Credit-Line\#: :text=The\%20Flexible\%20Credit\%20Line\%20(FCL,track\%20 records \%20in\%20economic\%20performance.

(2020d), "Mexico: Review Under the Flexible Credit Line Arrangement-Press Release and Staff Report" [en línea] https://www.imf.org/en/Publications/CR/Issues/2020/11/19/Mexico-Review-Under-the-FlexibleCredit-Line-Arrangement-Press-Release-and-Staff-Report-49907.

_ (2020e), "IMF Members' Quotas and Voting Power, and IMF Board of Governors" [en línea] https://www. imf.org/external/np/sec/memdir/members.aspx.

(2009), "El FMI reestructura sus mecanismos de crédito", Comunicado de Prensa, № 09/85, 24 de marzo [en línea] https://www.imf.org/en/News/Articles/2015/09/14/01/49/pr0985.

G-20 (2020), Statement Extraordinary G20 Finance Ministers and Central Bank Governors' Meeting. November 13 [en línea] https://www.mof.go.jp/english/international_policy/convention/g20/g20_201113_1.pdf.

Gavras, P. (2012), "Ratings game," Finance \& Development, vol. 49, № 1, marzo.

Humphrey, C. (2020), "All hands on deck: how to scale up multilateral financing to face the Covid-19 crisis", Briefing papers, ODI, abril.

Humphrey, C. y A. Prizzon (2020), "Scaling up multilateral bank finance for the Covid-19 recovery", ODI Insight, 18 de noviembre [en línea] https://www.odi.org/blogs/17570-scaling-multilateral-bank-finance-covid-19recovery\#review-of-mdbs.

Martin, E. (2021), "Latin America Bank Needs $\$ 80$ Billion Capital Hike, Head Says", Bloomberg, 3 de febrero [en línea] https://www.bloomberg.com/news/articles/2021-02-03/latin-america-bank-head-says-capitalboost-needed-for-recovery.

Mutua, D.C. (2021), "Chile Sells Biggest Latin American Sovereign Sustainability Bond", Bloomberg, 20 de enero [en línea] https://www.bloomberg.com/news/articles/2021-01-20/chile-sells-biggest-latin-americansovereign-sustainability-bond.

Ocampo, J. A. (2020), "La cooperación financiera internacional frente a la crisis económica latinoamericana", \#COVID19 Serie de Documentos de Política Pública, Nº 7, Nueva York, Programa de las Naciones Unidas para el Desarrollo (PNUD).

Paus, E. (2014), "Latin America and the middle-income trap", serie Financiamiento para el Desarrollo, № 250 (LC/L.3854), Santiago, Comisión Económica para América Latina y el Caribe (CEPAL).

Spence E. y A. Speciale (2020), "Bonds Linking Payout to Italy GDP Get Shrug From the Public", Bloomberg, 10 de julio [en línea] https://www.bloomberg.com/news/articles/2020-07-10/italy-s-debut-gdp-linked-bondssee-muted-demand-from-public.

Standard \& Poor's (2020), "Credit FAQ: COVID-19 and implications of temporary debt moratoriums for rated African sovereigns", 29 de abril [en línea] https://www.spglobal.com/ratings/en/research/articles/200429credit-faq-covid-19-and-implications-of-temporary-debt-moratoriums-for-rated-african-sovereigns-11451012.

Este Informe Especial es el décimo de una serie que elabora la Comisión Económica para América Latina y el Caribe (CEPAL) sobre la evolución y los efectos de la pandemia de COVID-19 en América Latina y el Caribe. Sus análisis económicos y sociales se actualizarán a medida que surja información relevante. La Secretaria Ejecutiva de la CEPAL, Alicia Bárcena, dirigió la elaboración de este Informe, con el apoyo técnico de la Oficina del Secretario Ejecutivo Adjunto, Mario Cimoli, y de Esteban Pérez Caldentey, Jefe de la Unidad de Financiamiento para el Desarrollo de la División de Desarrollo Económico de la CEPAL.

Copyright (C) Naciones Unidas, 2021 